Article

\title{
Towards the Development of Agenda 2063 Geo-Portal to Support Sustainable Development in Africa
}

\author{
Paidamwoyo Mhangara *, Asanda Lamba, Willard Mapurisa and Naledzani Mudau \\ South African National Space Agency, Earth Observation Directorate, Pretoria 0087, South Africa \\ * Correspondence: pmangara@sansa.org.za
}

Received: 30 June 2019; Accepted: 30 August 2019; Published: 6 September 2019

\begin{abstract}
The successful implementation of the African Union's Agenda 2063 strategic development blueprint is critical for the attainment of economic development, social prosperity, political stability, protection, and regional integration in Africa. Agenda 2063 is a strategic and endogenous development plan that seeks to strategically and competitively reposition the African continent to ensure poverty eradication and equitable people-centric socio-economic and technological transformation. Its impact areas include wealth creation, shared prosperity, sustainable environment, and transformative capacities. Monitoring and evaluation systems play a critical role in collecting, recording, storing, integrating, and evaluating and tracking performance information in the implementation of longer-term strategic plans. The usage of the geographic information system (GIS) as a monitoring and evaluation tool has gained traction in the last few decades due to its ability to support the collection, integration, storage, analysis, output, and distribution of location-based data. The advent of web-based GIS provides a powerful online platform to collect, integrate, discover, use and share geospatial data, information, and services related to sustainable development. In this paper, we aim to describe the implementation, architectural structural design, and the functionality of the pilot Agenda 2063 geoportal. The live prototype internet-based geoportal is intended to facilitate data collection, management, integration, analysis, and visualization of Agenda 2063 development indicators. This geoportal is meant to support the planning, implementation, and monitoring of the Agenda 2063 goals at the continental, regional, and national levels. As our results show, we successfully demonstrated that a web-geoportal is a powerful interactive platform to upload, access, explore, visualize, analyse, and disseminate geospatial data related to the sustainable development of the African continent. Although in the pilot phase, the geoportal demonstrates the primary functionality of geoportals in terms of its capability to discover, analyse, share, and download geospatial datasets.
\end{abstract}

Keywords: sustainable development; Agenda 2063; geoportal; monitoring and evaluation; GIS; geospatial data

\section{Introduction}

Africa's developmental trajectory, especially its social prosperity, economic development, public security and political stability, protection, and regional integration are largely hinged on the full implementation of the Agenda 2063 strategic blueprint [1-3]. Endorsed in January 2015 by the African Heads of State and Government at the 24th Ordinary Session of the Assembly of the African Union, Agenda 2063 is Africa's strategic development program that spells out the continent's economic and social aspirations over the long term [4]. Rooted in Pan-African principles of African solidarity, Agenda 2063 is an endogenous transformation plan that seeks to strategically and competitively reposition the African continent to ensure poverty eradication and equitable people-centric socio-economic and technological transformation. The continent's strategic objectives are broadly encapsulated into seven strategic aspirations that basically articulate the desired state of the African continent. In a nutshell, 
the aspirations endeavour to spell out Africa's vision regarding inclusive growth and sustainable development, continental integration and Pan-Africanism, good governance and democracy, peace and security, cultural identity and heritage, people-driven development, and the need to be a competitive and strong global player and partner [4-6]. Some of the strategic impact areas identified in the Agenda 2063 implementation plan include wealth creation, shared prosperity, sustainable environment, and transformative capacities [7]. Some of the indicators for wealth creation are access to electricity (\% of the population), access to clean water, annual gross domestic product (GDP) growth rate, and industrial development index in Africa. The indicators for sustainable environment include the annual change in forest area (\%), the sustainable nitrogen management index, terrestrial sites of biodiversity importance that are completely protected, and freshwater withdrawal as a $\%$ of total renewable water resources [6,7].

With a population of approximately 1.225 billion that is highly diverse from 54 countries, Africa is considered to possess the second biggest population in the world. Africa's population is estimated to be growing by at least $2.6 \%$ per annum and is estimated to reach 2.5 billion by 2050 [8]. Since 1995, Africa has experienced considerable economic development; in fact, it is the second-fastest developing area in the world. Africa's economic performance is partially attributable to its huge landmass and ocean territory that hosts rich natural resources such as minerals, oil, natural gas, timber, and extensive swaths of rich agricultural lands. Considering Africa's huge landmass and diverse geography, the accomplishment of the Agenda 2063 goals requires systematic spatial planning and data collection, monitoring, evaluation, and consolidation. The aspirations, goals, priority areas, and targets articulated in the Agenda 2063 strategic blueprints are inherently geographic in nature as they all occur in space (location) and time. To this end, geographical information science (GISc), particularly geographic information systems (GIS), earth observation, and global navigation satellite systems can play a fundamental role in supporting the attainment of the Agenda 2063 targets through data collection, storage, integration, evaluation, and reporting.

Since the dawn of human civilization, geographical information tools such as maps and compasses have played a fundamental role in guiding mankind's developmental agenda. Given that location plays a critical role in spatial and public infrastructure development planning, maps have played an integral role in territorial planning, cooperation, navigation, and conflict resolution for many centuries. Historically, maps were also used extensively in the discovery of new territories and natural resources. In the last few decades, the rapid and simultaneous technological developments in computer science, satellite communication, navigation, and earth observation systems have widened the scope of the usage of GISc in many areas of sustainable development $[9,10]$. For many decades now, many countries have been exploiting GIS for regional and spatial planning [11,12], although in a siloed manner. It is widely acknowledged that location plays a central role in integrating information about the society, the economy, and the environment $[13,14]$. In addition, cross-border challenges such as climate change, disasters, peace and security, and quality of the environment can only be solved through coordinated global and regional efforts $[2,15,16]$. In recognition of the power geographical locations and geospatial information play in development planning, the United Nations Statistical Commission endorsed a work program in 2013 to develop a statistical spatial framework that would become an international standard for the integration of statistical and geospatial information [17]. This endorsement comes following the pioneering work done by the UN Global Geospatial Information Management (UN-GGIM) since 2011 to create a framework and define protocols to integrate statistics and geoinformation data processes [18]. The critical role played by timely and consistent geographic information in supporting sustainable development is widely acknowledged by the Group on Earth Observations (GEO) and the Committee of Earth Observation Satellites (CEOS) through their dedicated efforts in coordinating earth observation initiatives globally and advocating for the use of open and free satellite data. The role played by earth observation technology in supporting sustainable development goals is well described in many publications [19-21]. 
The practical implementation of the African Union (AU) Agenda 2063 blueprint is squarely contingent on the efficient and effective execution of this ambitious and transformative strategic plan. Notably, the strength of any strategic plan lies in its execution capability. Monitoring and evaluation systems play a critical role in collecting, recording, storing, integrating, and evaluating and tracking performance information in the implementation of longer-term strategic plans. Monitoring is the continuous assessment of a plan in relation to the set implementation schedule that is used to provide continuous feedback to management on the implementation progress of the set programme to enable managers to take timely decisions based on identifying successes and constraints. The evaluation uses the data and information provided by a monitoring system to facilitate the analysis of trends and impacts of the programme. Monitoring and evaluation systems are not a new concept, many governments and international institutions have been using them for many years. The practice and culture of monitoring and evaluation are well embedded in organisations such as the United Nations, the World Bank Group and the Organisation for Economic Co-operation and Development (OECD). The United Nations Development Programme (UNDP), for instance, published a handbook to guide the planning, monitoring, and evaluation for development results [22]. The 2009 version of the UNDP handbook [22] integrates planning, monitoring, and evaluation into a single guidebook aimed at inculcating the application of a results-based approach in programming and performance management in order to support the UN development agenda, the Millennium Development Goals (MDGs), at that time. It provides a robust Results Based Management (RBM) results chain that shows the process flow from the inputs, activities, outputs, outcomes, and impacts and the linkage between resources and results. The RBM results chain effectively encapsulates the planning and implementation processes and addresses pertinent strategic planning questions related to execution and impacts. The usage of the GIS as a monitoring and evaluation tool has gained traction in the last few decades due to its ability to support the collection, integration, storage, analysis, output, and distribution of location-based data. While the use of GIS in monitoring and evaluation adds significant value to the current methodologies, most GIS implementations remain institutional without any capability to serve users across institutions, national boundaries, and diverse geographic locations.

The advent of web-based GIS provides a powerful online platform to collect, integrate, discover, use, and share geospatial data, information, and services related to sustainable development [23]. Web-based GIS systems are extending the gamut of geospatial data uses and are helping in improving the update and distribution of spatial data. Cooperative spatial data entry, updates, and management across administrative and political jurisdictions are increasingly becoming feasible using internet-based depots. Geoportals provide a powerful internet-based platform for finding and accessing geospatial information and related geographic services such as sharing, displaying, editing, analysing, and publishing geographic information online [24]. The importance of geoportals as part of spatial data infrastructure is emphasized by Maguire [23]. To support and optimize the widespread application geographic information, most institutions are adopting the use of geoportals to facilitate the discovery, dissemination, and sharing of geospatial information [11,25-29]. The proliferation of geoportals is enabling quick and direct access to geographic data sets of various formats such as satellite imagery, land use, and land cover data sets, and vector layers related to administrative boundaries, transport network layers, and demographic datasets. The geo-visualization capability provided by some deputies enables interactive techniques for visualizing geospatial metadata and information. The growing importance of geoportals is succinctly captured by Crompvoets [30] who sees geoportals as a one-stop-shop for the discovery and assessment of geo-information products and services with significant cost savings. This point is reiterated by Vockner [24] who highlights that geoportals are the main gateways to find, evaluate, and use geographic information. The design and development of most geoportals are largely influenced by the concept of service-oriented architectures (SOA) and the principles and standards prescribed in the Open Geospatial Consortium (OGC), particularly the catalogue service web (CSW) norms [24]. Some of the geoportals that have been successfully implemented to promote and govern the sharing and reuse of geospatial data include the Infrastructure for Spatial Information 
in the European Community (INSPIRE) Geoportal-European Community Infrastructure for Spatial Information, GeoPortal. Bund for Germany, Geoportail in France, GeoNorge in Norway, and IDEE in Spain [28].

In a recent review of international and national geoportals, an inventory by Jiang [31] showed that most of the geoportals were developed with the prime objective of serving as an electronic infrastructure for e-government and as dissemination platforms for open government data. Some mature national geoportals include Canadas' Open Data, France's geoportal, India's geoportal, United States Geospatial One-Stop, US's geoportal, and China's geoportal. Largely, these portals aim to provide a web platform to enable the sharing of national datasets to increase transparency and accountability in government. Other popular geoportals such as INSPIRE are targeted towards the provision of geospatial datasets to member states of the European Union. Space agencies, surveying, and mapping bureaus are also at the forefront of providing geoportals for the dissemination of satellite data, aerial photography, maps, and other digital geospatial datasets [32]. Popular examples include the European Space Agency (ESA), Copernicus Open Access Hub, and NASA Earth data portal.

Lately, several geoportals have also been launched in Africa. In our review of African geoportals, we observed that most geoportals serve as platforms for geospatial data dissemination for specific projects, examples include the MESA SADC Geoportal, National OCIMS Geoportal, and the WASCAL Geoportal. A similar observation was made for continental, regional, and national geoportals such as the RCMRD Geoportal, Africa Geoportal, and GeoCameron. From our assessment, the current geoportals are not specifically aimed at tracking Agenda 2063 development indicators but serve as online geospatial data distribution platforms. In many cases, the geoportals also lack the basic analytical capability and spatial analysis functionality. While several geoportals already exist internationally as recently reviewed by Jiang [31], currently none of them are targeted towards the monitoring and evaluation needs of Agenda 2063 on a continental scale. Similarly, an inventory of geoportals done by Jiang [31] clearly shows that African countries lack a common online platform for uploading, access, visualizing, storing, analysing, and disseminating development information related to Agenda 2063. To bridge the gaps, there is a need to provide a geoportal dedicated to the monitoring of Agenda 2063 development indicators that has analytical and spatial analysis capability.

To achieve its strategic goals, the African Union (AU) seeks to strengthen its capacity to collect, analyse, and evaluate data to support the implementation of its developmental agenda [4-6]. Acute shortage of data to support the monitoring, evaluation, and comparison of developmental programmes has been stressed as one of the problems facing Africa. AU affirms that the implementation of the Agenda 2063 strategic plan is knowledge-driven and requires both qualitative and quantitative data to support monitoring and evaluation. In the same vein, AU recognises the need for monitoring and evaluation systems at country, regional, economic, community, and continental level to track the implementation of the set targets. The plan also emphasizes the need for the establishment of a common platform to facilitate the preparation of integrated monitoring and evaluation reports. Furthermore, the need to generate reliable, timely, and disaggregated data using appropriate systems for accurate reporting has been highlighted as critical to supporting evidence-based planning.

Recalling that Agenda 2063 aims to achieve socio-economic and political transformation through the optimum use of natural resources, the use of geographic information becomes instructive. Sustainable development is an inherently complex process due to the complex interlinking of information domains that require consideration. The usage of geographic datasets and information systems for planning and decision support permeates across the entire spectrum of sustainable natural resource management. The fusion of web mapping services, spatial visualization, and analysis have considerable potential to support the monitoring and evaluation of sustainable development goals. The South Africa National Space Agency (SANSA) in partnership with New Partnership for Africa's Development-African Union Development Agency (NEPAD-AUDA), the implementing arm of the African Union, has developed a live prototype internet-based geoportal to facilitate data collection, management, integration, analysis, and visualization of Agenda 2063 development 
indicators. The geoportal is aimed at supporting the planning, implementation, and monitoring of Agenda 2063 goals at continental, regional, and national levels. In this paper, we aim to describe the implementation, structural design, and the functionality of the pilot Agenda 2063 geoportal. Based on the monitoring and evaluation requirements from NEPAD-AUDA, we specifically aim to demonstrate the ability of the geoportal to uploading, accessing, visualizing, storing, analysing, and comparing development information related to the wealth creation, share prosperity, and transformative capacity impact indicators. Selected wealth creation indicators encompassed manufacturing value addition, access to electricity, and improved water sources. Shared prosperity indicators included incidences of tuberculosis, the prevalence of Human immunodeficiency virus (HIV), unemployment with intermediate education, the mortality rate for children under five, and incidences of malaria and gross national income (GNI) per capita growth. Lastly, tax revenue was used as a transformative capacities indicator. Typical users for the geoportal include planning officers from African Union member states, regional economic communities, international development institutions, development aid partners, and funders, NEPAD-AUDA, African Union Commission (AUC), and the public.

\section{Data}

The success of a geoportal is partly dependent on the availability of the relevant data accessible on the web portal and the frequency at which the data is updated. Several statistical, vector, and raster datasets were sourced from different data providers and uploaded into the geoportal. We obtained statistical socio-economic data from the World Bank, NEPAD-AUDA, and Statistics South Africa to populate the database for this geoportal. The statistical data acquired related to the shared prosperity indicators such as incidence of tuberculosis, the prevalence of HIV, unemployment with intermediate education, the mortality rate for children under five, incidences of malaria, and GNI per capita growth. Data on wealth creation indicators included manufacturing value addition, access to electricity, and improved water sources. Tax revenue data were used as an indicator for transformative capacities indicator. Most of these socio-economic data is updated at least yearly by most countries. Raster and vector data layers were added to provide a spatial and environmental perspective of the situation in various countries. Raster layers consisted of gridded data such as Landsat 8 satellite data acquired from SANSA. The vector datasets layers are comprised of points, line and polygon layers for roads, electricity power lines, administrative boundaries, health service facilities, educational facilities, disaster vulnerability atlas, telecommunication lines, geological maps, rivers, water bodies, and an open street map layer. The vector and raster data were projected to the World Geodetic System (WGS) 84 datum geographic coordinate system. This data are comprised of spatial and non-spatial data. Spatial data included the vector and raster datasets that can be georeferenced to a location on the earth's surface while non-spatial data does not refer to a specific location. While non-spatial data are normally delivered in spreadsheet formats, raster data are supplied in various formats that include GeoTiff, Tiff, JPG, NetCDF, and PNG while vector files are delivered as ESRI shapefiles and other standard textural formats such as KML, GML, GeoJSON, GeoHash, and WKT. The storage, retrieval, visualization, rendering, conversion, and manipulation of vector and raster spatial data and their formats require relational database schemas with GIS functionality as outlined in the architectural design.

\section{Geoportal Implementation Framework}

In this section, we concisely describe the main processes involved in the development of the Agenda 2063 Geoportal. Concurrent engineering was used to fast-track the development of the pilot geoportal. The prototype geoportal was designed to demonstrate the concept of integrated planning, monitoring, and evaluation in a practical and tangible manner. The functionality of a geoportal can be assessed in terms of its functionality for end-users, geoportal management, geoportal data security, geoportal interoperability, and interface customization [33]. At the pilot phase, we prioritized the functionality of the geoportal in terms of its functionality to end-users, geoportal management, and geoportal data security. End-user functionality would consider aspects such as the discovery of 
geospatial data resources, a preview of geospatial datasets, and registration of portal users. To achieve this, end-user engagement was concurrently done with portal development.

\subsection{Architectural Design}

The architectural design of the Agenda 2063 Geoportal is based on three application layers as illustrated in Figure 1. PostgreSQL[a] client/server, conceptual model (refer to the PostgreSQL 11.3 Documentation: The PostgreSQL Global Development Group, 2019). An overview of the architectural design of the Agenda 2063 Geoportal is shown in Figure 1 below.

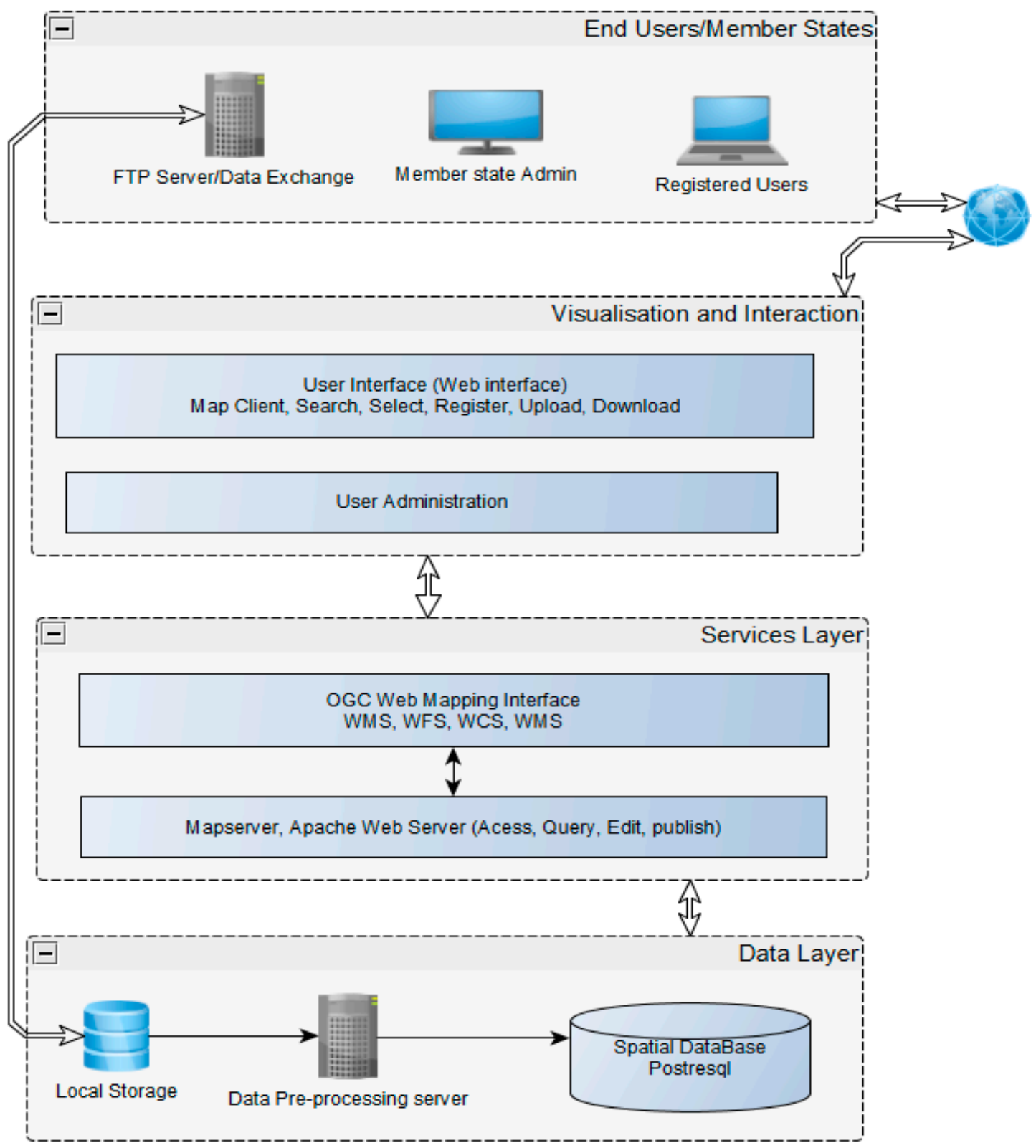

Figure 1. Application layers for the Agenda 2063 Geoportal. Three application layers were implemented for the geoportal.

The first application layer is the database layer that stores and serves all Sustainable Development Goals (SDGs) dataset sourced from different countries. PostgreSQL database with PostGIS extension was selected in the implementation of the geoportal due to its ability to deal with both spatial and non-spatial data types. This then ensured that any data types from 54 African countries can be stored. 
PostgreSQL has a proven capacity to deal with a range of large geographical datasets that include vector, raster, and numerical data. PostgreSQL is an open-source object-relational database management system (ORDBMS) that uses a client/server model. In addition to being open-source, some of the attractive features offered by PostgreSQL include its ability to handle complex queries, multi-version concurrency control, triggers, update views, transactional integrity, security enforcement, and its capability to handle foreign key. The backend server-side processes are responsible for managing the database files by accepting connections from client applications and executing the requested database actions using a dataset server program known as PostgreSQL. Some of the basic functions for the server-side include data storage and transformation.

The second layer consists of a data services layer that allows for access, processing, and sharing of data stored in the database. This layer allows for the publishing of interactive maps and spatial data to the web for consumption by various web mapping applications with map visualization capabilities. MapServer, an open-source platform, was used to publish this data is an application-independent manner by using OGC standards thus achieving data interoperability that will allow the sharing of this data with other organisations.

The third layer is the visualisation layer which serves two main purposes namely, the display of data served from the database for the visualisation and the capture of data queries from the users and pass it on the database via the services layer. The results of these queries are also viewed from the visualisation layer. Visualisation is achieved via a web user interface that provides user administration functionalities.

\subsection{Tools and Resources}

The portal was developed using an ensemble of cross-platform programming and scripting languages that can be used on various operating platforms such as Windows, Linux, and UNIX. The portal's front-end user interface was developed using ExtJS[c] version 6 and GeoExt[d] version 2. Ext]S is a cross-platform web application JavaScript framework and interactive application. GeoExt is also a JavaScript framework cross-platform application that adds Open Layers[e] and GIS functionalities into ExtJS. Agenda 2063 Geoportal uses PHP[f] (Hypertext Pre-processor) open-source, cross-platform language as a server-side language for database querying, deleting, updating, and adding new data. The portal also uses MapServer[g], an open-source, cross-platform application to publish the maps. MapServer uses PostGIS[h] and GeoExt to display the published interactive maps. Figure 2 below provides a concise depiction of the interactions between the front-end and the backend of the Geoportal.

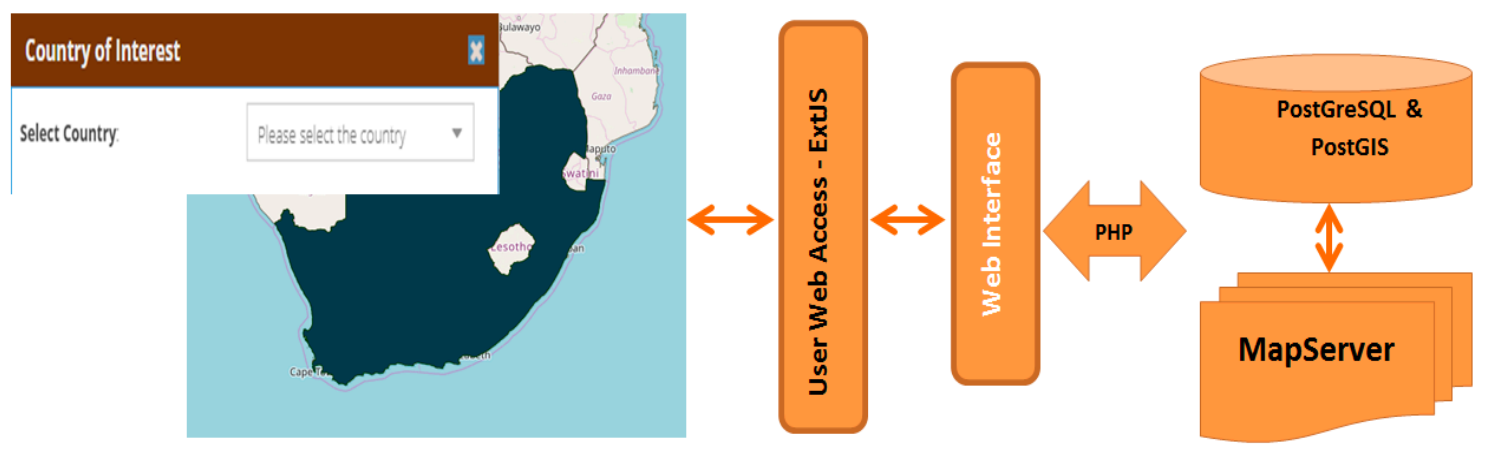

Figure 2. Example of a user query pipeline. Country selection examples from a user click query.

\subsection{Implementation of the Backend: Databases}

The backend PostgreSQL database management system was spatially enabled using the PostGIS extension. PostGIS, through its generic index structure (GIST), embeds the spatial functionality to enable PostgreSQL to efficiently handle spatial data, indexes, GIS algorithms, and geographical analysis functions. The integration of PostGIS was done through the data connection method aimed 
at upgrading the PostgreSQL object-relational database into a backend spatial database with GIS capability. Moreover, PostGIS adds indexing, transaction, and concurrency functionality to PostgreSQL. PostgreSQL is a robust object-orientated relational database management system with a proven ability to work in high volume environments. It is ACID (atomicity, consistency, isolation, and durability) compliant. MapServer was integrated to support the display of dynamic geospatial maps over the internet. It supports the display and querying of raster and vector datasets from the database. Aside from querying capabilities, the integration of MapServer was aimed at enabling on the fly projections, spatial analysis and editing, high-quality rendering, cross-platform compatibility, and data interoperability. It has client and backend functionality, enabling the implementation of a hybrid architectural design that is known to improve system efficiency and online geospatial analysis.

\subsection{Implementation of the Web Front-End: Geospatial Services}

The Agenda 2063 Geoportal aims to provide a wide range of client geospatial web services to African countries. Key among them is the ability to discover, visualize, access, retrieve, compare, and download spatial data sets related to agenda 2063 goals. To build the front-end of the geoportal we integrated map service, feature service, and image service functionality into the web interface. The processes for data access and retrieval are depicted in Figure 2 above. As depicted in the flow chart above, various operations are supported by the web application front end. A selection operation for a country of interest is illustrated where a user click is used to query the database and return a country of interest. Similar operations are supported for selecting and displaying country indicators and statistical information that is then analysed and compared by various charting options provided by the front end.

Three levels of user access were defined in the design of the geoportal. The general user access level is aimed at the general public. At this level, users can use some of the most basic functionality of the geoportal which includes visualization of the geospatial datasets available on the portal. The general public is required to register and login to access additional geospatial services, such as charting for comparing development data from countries and regions. To protect the integrity of some sensitive datasets, access rights are validated using a filter once a user has logged in. User rights are administered by the national statistical offices. The data administrators are responsible for data verification, data uploading, and data integrity and data access in their own countries. A system administrator is assigned responsibility for managing the computer systems, web pages, databases, security threats, and the environment where the system is operating.

Since MapServer was utilized in achieving data interoperability, through OGC data sharing standards, datasets can be served to third-party visualization platforms such as QGIS and ArcMap by WMSs. When the user requests data from the portal, the portal first validates the user access rights and once permission has been granted the data is retrieved from the host server database and sent back to the user. The retrieval process is in line with the Open Geospatial Consortium[i] standard for web mapping as shown in Figure 3 below.

\subsection{Geospatial Datasets and Development Indicators}

Agenda 2063 has 20 strategic goals that crosscut the seven aspirations described earlier. For demonstration purposes, we selected a few economic and health development indicators to showcase the functionality of the geoportal. Development indicators used in the development of the geoportal include GNI per capita growth (annual \%), mortality rate for children under five years per 1000 live births, access to electricity (\% of population), unemployment with intermediate education, improved water sources, tax revenue (\% of GDP), prevalence of HIV, total (\% of population), manufacturing, value added (\% of GDP), incidences of tuberculosis (per 1000 people) and incidences of malaria. Our aim was to use public domain datasets. We integrated a number of geospatial datasets to supplement visual analysis and these include vector and raster data layers. The vector and raster layers include base layers of member states, transport networks, geology, population, industry, information 
and communication networks, human settlements, disaster, sustainable land and water management, energy, health services, education, and satellite imagery.

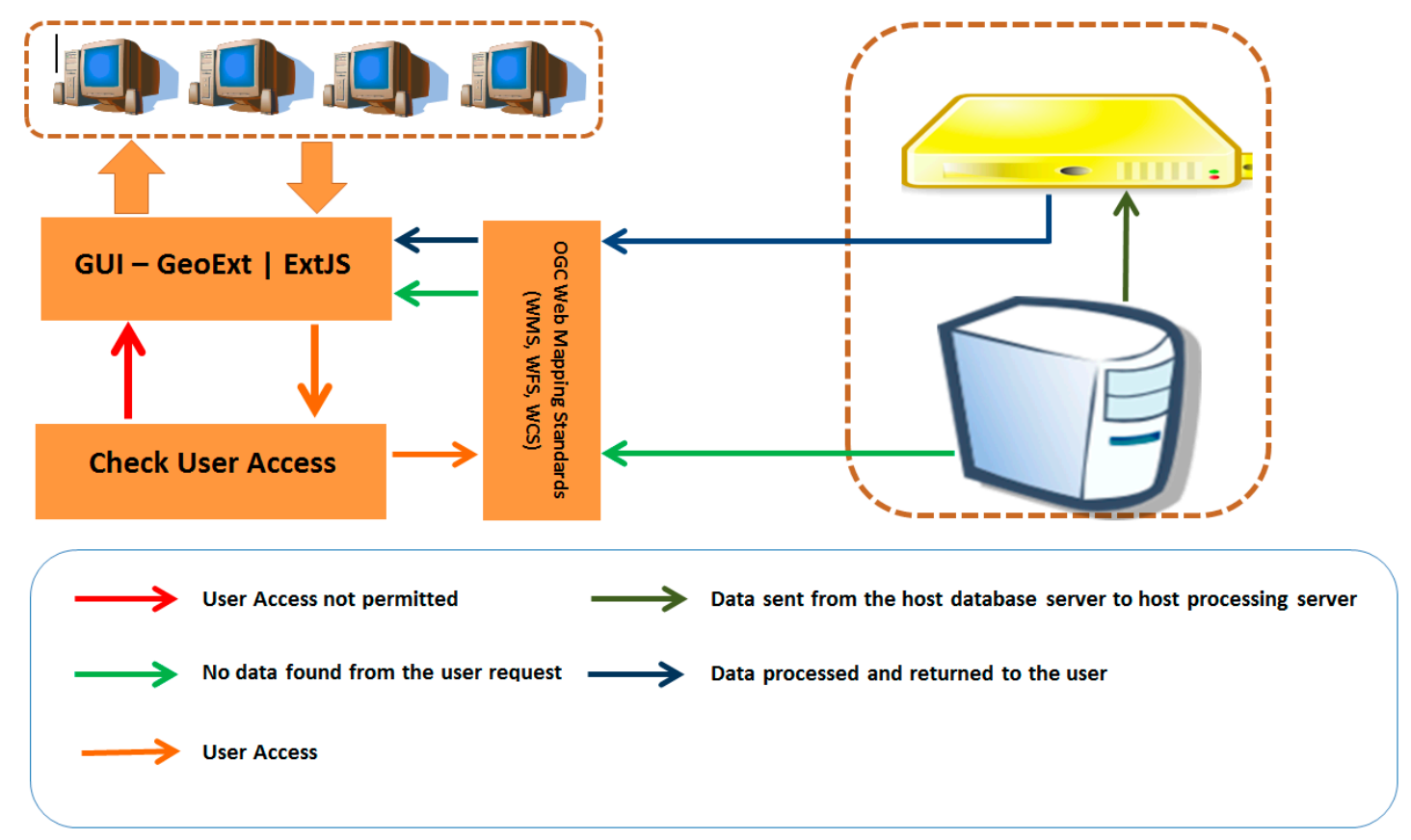

Figure 3. Data access restrictions. Data interoperability is achieved using Open Geospatial Consortium (OGC) standards. However, access to sensitive datasets is restricted at the user level.

\subsection{Awareness and User Requirements Collection Seminars}

We conducted seminars with officers involved in planning, monitoring, and evaluation to raise awareness on the value of the Agenda 2063 geoportal as a tool to support integrated spatial planning, monitoring, evaluation, and reporting. A second objective of the seminars to collect user requirements and understand the current monitoring systems and evaluation systems currently in use. The participants were drawn from Niger, Southern African Development Community (SADC), East African Community (EAC), the Intergovernmental Authority on Development (IGAD), NEPAD-AUDA, and the AUC. The seminars we conducted in Durban and Johannesburg in South Africa and Niamey in Niger. Awareness sessions we also conducted by NEPAD-AUDA in various African countries.

\subsection{Hardware Infrastructure}

The pilot geoportal application was deployed on a development server with 300 GB storage capacity, 32 GB memory, 2 processor sockets, each with 16 cores. A storage server with over 30TB of storage space was mounted on the deployed server for storing the large continental base layer datasets.

\section{Demonstration}

In this section, we aim to present the functionality of the prototype geoportal. We will showcase its front, user access, and data upload interfaces, development indicators, and charting capabilities. Furthermore, we will demonstrate the ability of the geoportal to display development trends such as access to electricity, manufacturing value addition, GNI per capita growth, and tax revenue information. We also highlight the geoportal's capability to tabulate inter-country comparisons of specified development indicators. The visual and integration functions are depicted by applying map overlay operations using the human settlements layer and SPOT 6 satellite imagery.

The Agenda 2063 Geoportal shown in Figure 4 in this project demonstrates that geoportals are a powerful web-based interactive platform to upload, access, explore, visualize, analyse, and disseminate geospatial data related to the sustainable development of the African continent. Although in the pilot 
phase, the Geoportal demonstrates the primary functionality of geoportals in terms of its capability to discover, analyse, share, and download geospatial datasets as evident on the following web link: http://agenda63sdgs.sansa.org.za/nepad/.

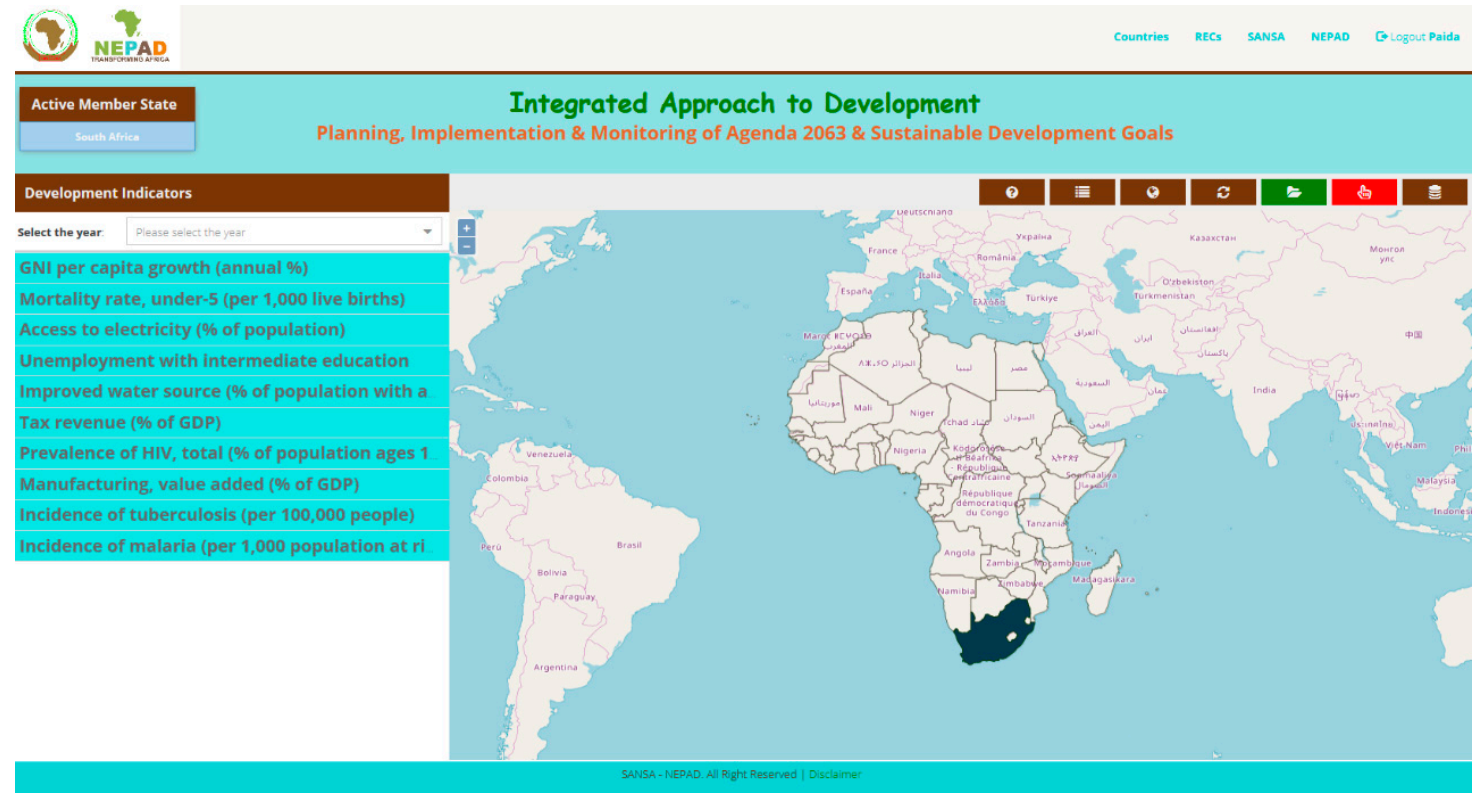

Figure 4. Front end interface for interacting with the geoportal.

In this case, we used a number a geo-datasets such as statistical development indicators, demographic statistics, satellite imagery, vector data sets for transport networks, and administrative boundaries, hazard layers, land use and land cover base layers, and digital elevation models as shown by the product layers in Figure 5 .

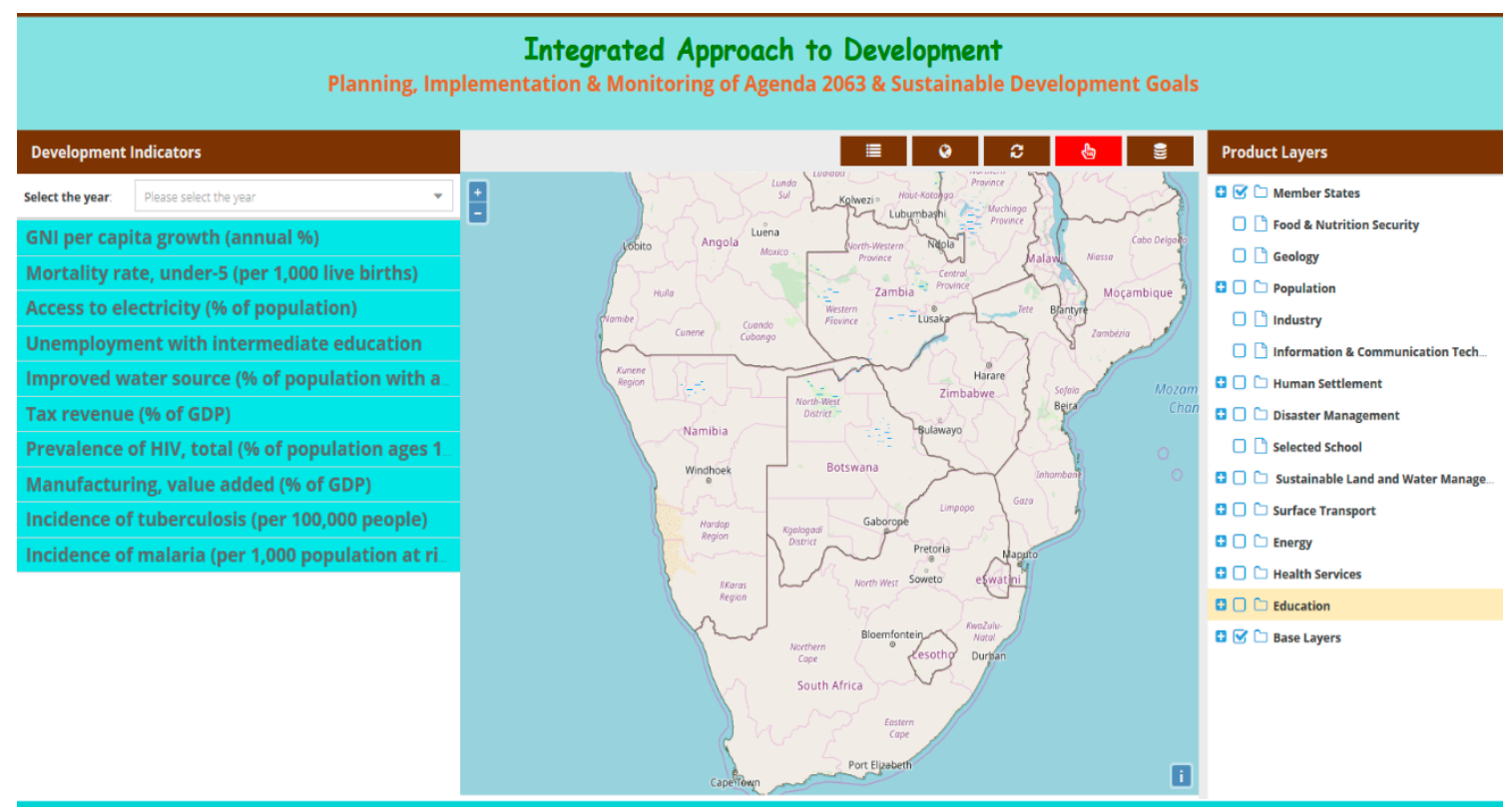

Figure 5. Base layers can be viewed on the maps and overlaid for visual and quantitative analysis.

The interactive nature of the Geoportal allows the overlay of vector and raster datasets and to make comparisons between countries, regions, and provinces aided by graphical analysis. The browsing and viewing capability are aimed at the general public and more advanced functionality such as graphical 
comparisons is designed for authorized users of the geoportal. In order to protect the integrity and confidentiality of the datasets, three levels are users are designated. Access to information and more advanced functionality of the geoportal is granted through user registration and password security as shown in Figure 6 below.

\section{User Login Window}

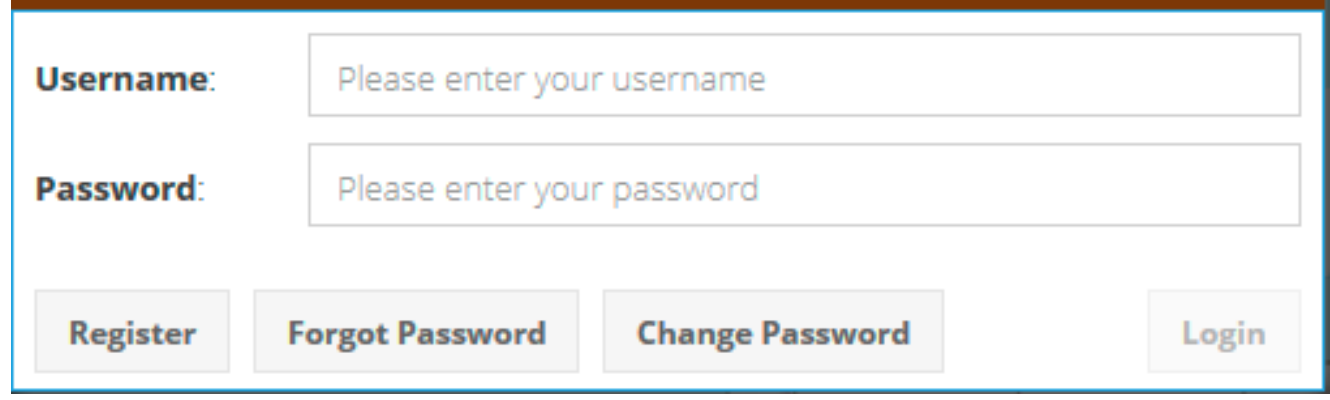

Figure 6. User rights administration.

The geoportal has the capability to allow authorized officials from national statistical offices to independently upload official datasets as shown in Figure 7 below.

\section{Upload Data}

\begin{tabular}{|c|c|c|c|}
\hline \multirow{2}{*}{$\begin{array}{l}\text { Country: } \\
\text { South Africa }\end{array}$} & \multicolumn{3}{|c|}{ Focal Instituition: } \\
\hline & $\nabla$ & National Statistics Office & $\boldsymbol{\nabla}$ \\
\hline Product Database: & Population & & $\nabla$ \\
\hline Help & & & Next \\
\hline
\end{tabular}

Figure 7. Data upload capabilities for data updating and sharing.

In this geoportal, we selected several development indicators related to the strategic impact areas of shared prosperity, wealth creation, and transformative capacities. The snapshot in Figure 8 below illustrates the results of our implementation. We show for each country, the high-level strategic impact, the indicator, and the Agenda 2063 target.

\begin{tabular}{|c|c|c|c|}
\hline \multicolumn{4}{|c|}{ Development Indicators } \\
\hline Country & Strategic Impact & Indicator & Agenda 2063 Target \\
\hline South Africa & Shared Prosperity & Incidence of tuberculosis (per 100,000 people) & Reduce the 2013 incidence TB by at least 80\% \\
\hline South Africa & Shared Prosperity & Prevalence of HV, total (\% of population ages 15-49) & Reduce the 2013 incidence of HIV/AIIDs by at least $80 \%$ \\
\hline South Africa & Shared Prosperity & Unemployment with intermediate education & \\
\hline South Africa & Shared Prosperity & Mortalty rate, under -5 (per 1,000 live births) & Reduce 2013 child mortality rates by at least 5096 \\
\hline South Africa & Shared Prosperity & Incidence of malaria (per 1,000 population at risk) & Reduce the 2013 incidence of Malaria by at least $80 \%$ \\
\hline South Africa & Transormative Capacities & Tax revenue (yo of GDP) & Tax and non-tax revenue of al levels of government should cover at least $75 \%$ of current and developme. \\
\hline South Africa & Shared Prosperity & GNI per capita growth (annual 96) & Increase 2013 per capta income by at least $30 \% 6$ \\
\hline South Africa & Wealth Creation & Access to electricity (9s of population) & Increase access and use of electricity and internet by at leass. $50 \%$ of the 2013 leves \\
\hline South Africa & Wealth Creation & Improved water source (96 of population with access) & Reduce 2013 level of proportion of the population without access to safe drinking water by $95 \%$. \\
\hline South Africa & Wealth Creation & Manufacturing, value added (96 of GDP) & Real value of manufacturing in GDP is $50 \%$ more than the 2013 level \\
\hline
\end{tabular}

Figure 8. High-level strategic impacts, indicators, and the Agenda 2063 targets. 
The charting capability of the geoportal is demonstrated in Figures 9 and 10 below. We show the ability of the geoportal to provide graphical plots of the development indicators over time to support trend analysis. In this paper, we used the access to electricity development indicator to showcase the geoportal graphical plotting capabilities.

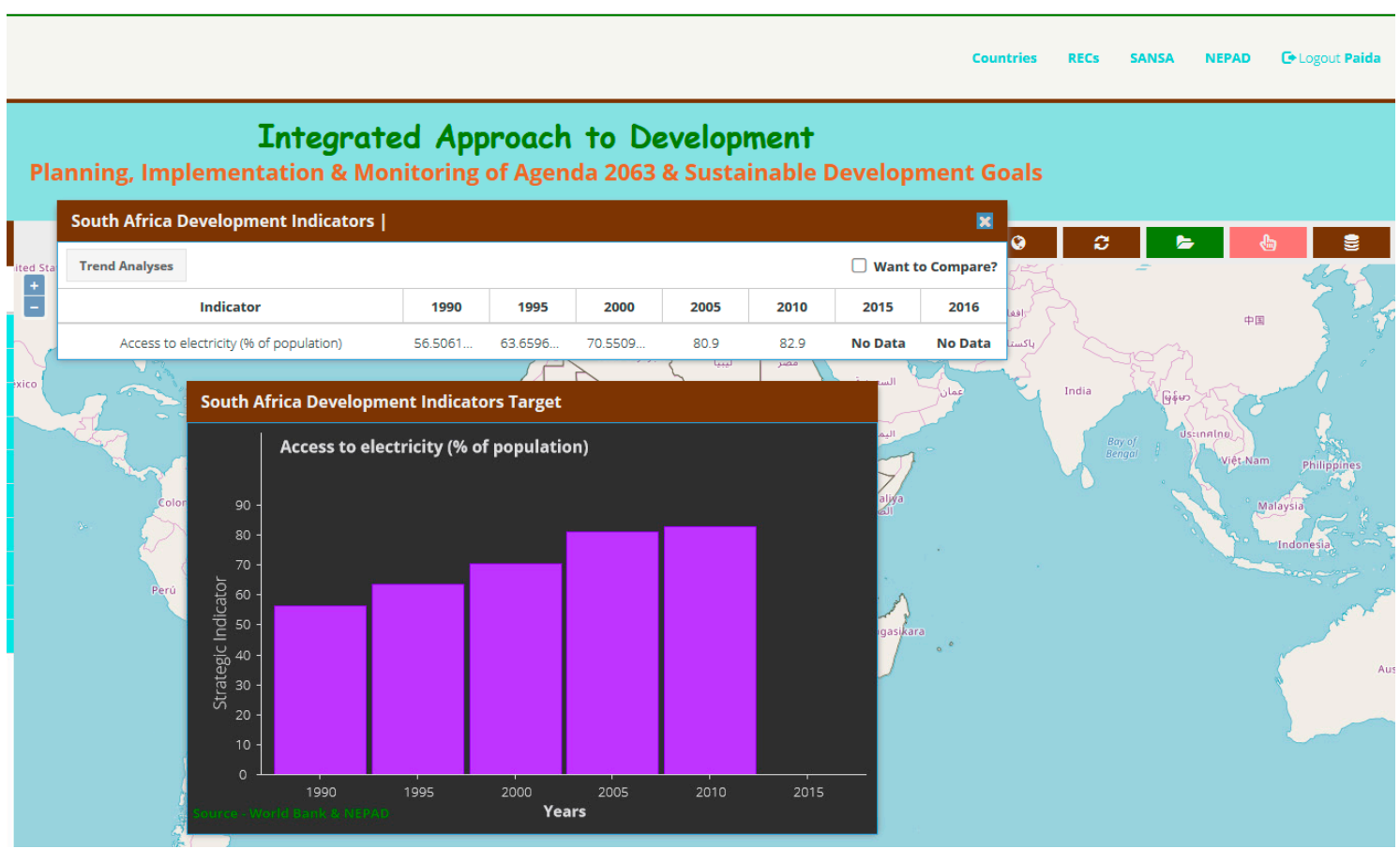

Figure 9. Charting options are provided by the front end for visual analysis.

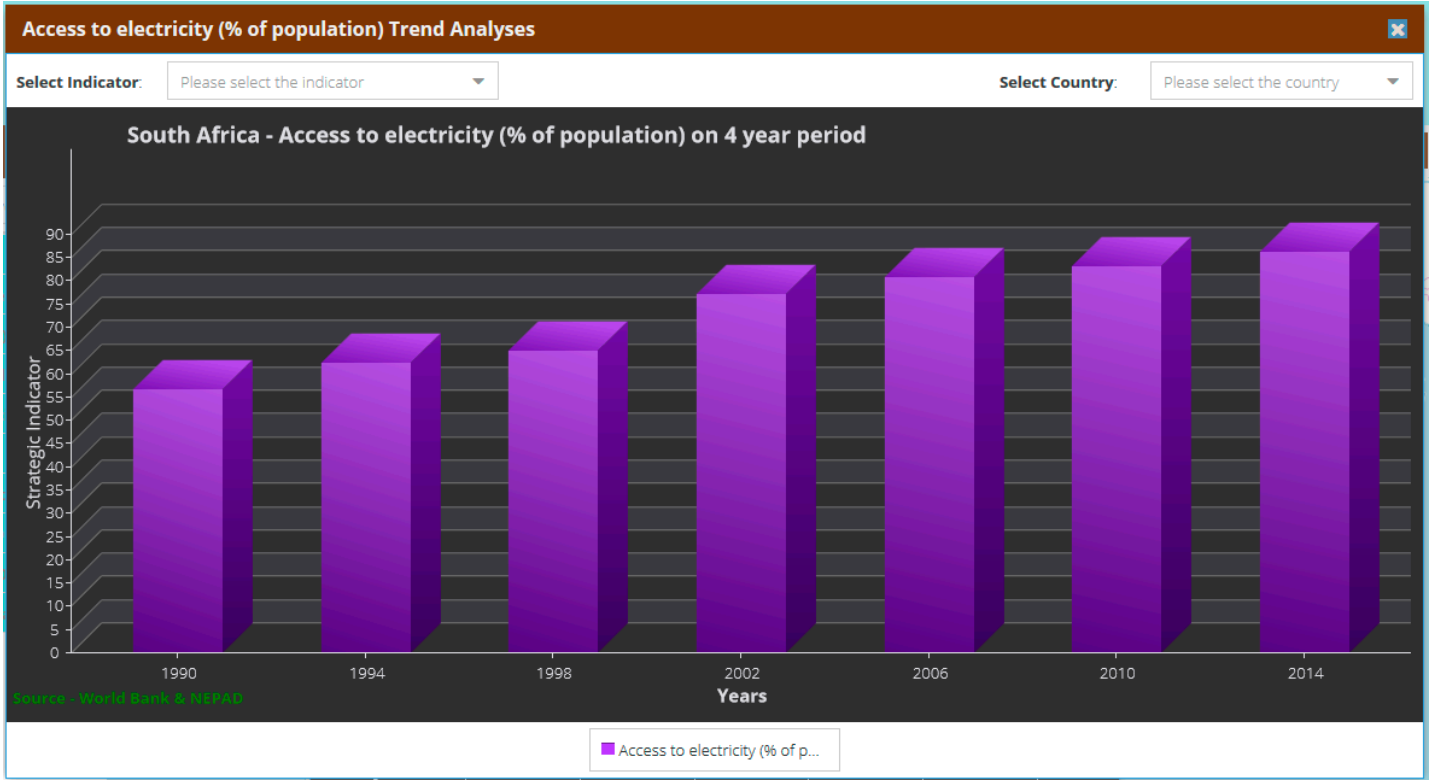

Figure 10. Example of a chart displaying the percentage of the population with access to electricity and how this varies over time.

Comparison of development indicators between different member states and regional economic communities is another essential function offered by the geoportal as shown in Figure 11. This functionality allows users to compare the rates of development among African states and learn from the 
different developments interventions implemented in countries that show better growth. A comparison of access to electricity shown below for South Africa, Botswana, Zambia, and Zimbabwe.

\begin{tabular}{|c|c|c|c|c|c|c|c|c|c|c|c|c|c|c|c|c|}
\hline & Member States $\uparrow$ & Region & Member State.... & 1990 & 1992 & 1994 & 1996 & 1998 & 2000 & 2002 & 2004 & 2006 & 2008 & 2010 & 2012 & 2014 \\
\hline 0 & Algeria & Northern Africa & Botswana & $5.807 \ldots$ & $10.15 \ldots$ & $14.48 .$. & $18.78 . .$. & $23.03 \ldots$ & 27.2. & $31.3 .$. & 35.4 & $39.6 .$. & 43.1 & 48.0... & 52.2. & $56.4 \ldots$ \\
\hline 0 & Angola & Southern Africa & Equatorial Guinea & $54.83 \ldots$ & $56.01 \ldots$ & $57.18 .$. & $58.32 \ldots$ & $59.40 . \ldots$ & $60.4 \ldots$ & $61.3 .$. & 62.3 & $63.3 .$. & $643 .$. & 65.4. & 66.4. & 67.5 \\
\hline 0 & Benin & Western Africa & South Africa & $56.50 \ldots$ & $59.37 \ldots$ & $62.23 \ldots$ & 57.6 & 64.9 & $70.5 \ldots$ & 77.1 & 80.9 & 80.7 & 81.9 & 82.9 & 85.3 & 86 \\
\hline 0 & Botswana & Southern Africa & Zambia & 13.9 & 19.2 & $16.15 \ldots$ & 17.3 & 17.87... & 16.7 & 17.4 & 20.3 & $20.7 \ldots$ & 21.5... & 22 & 23.1... & 27.9 \\
\hline
\end{tabular}

Figure 11. Data comparison for four countries. Access to electricity comparison.

The ability to query a geoportal is critical for many users. Here, we demonstrate this functionality by querying the education test dataset as shown in Figure 12 below.

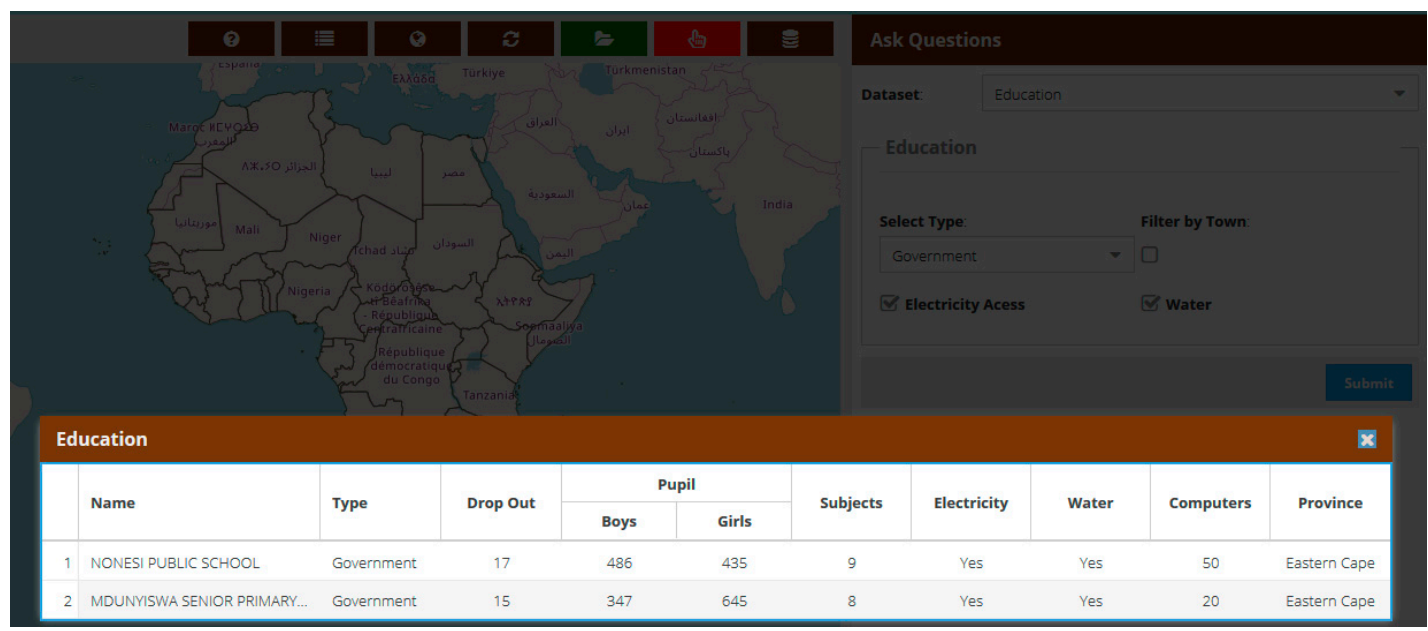

Figure 12. Education information queries displayed by the front end.

Information regarding the strategic impact areas can also be graphically displayed on the geoportal. Figure 13 below illustrates the temporal trends for manufacturing, value-added from 1990 to 2015 and shows the expected target. For manufacturing, the value added is a wealth creation indicator. Similarly, the GNI per capita growth is shown in Figure 14 and mortality rate trends are shown in Figure 15 for the same period. GNI per capita growth and mortality rate for children are the five years, and are both shared prosperity indicators. Tax revenue, a transformative capacity indicator is shown in Figure 16.

The strength of the Agenda 2063 lies in its ability to integrate and visualize the various statistical development indicators with geographical vector and raster datasets. In Figure 17, we show the ability of the geoportal to display human settlements layers over the city of Niamey in Niger.

Satellite images provide a powerful means of visualizing urban and rural landscapes over time. They provide a synoptic view of the environment and provide visual evidence of sustainable development on the ground. Figure 18 below illustrates the capability of the portal to display satellite imagery as visual evidence in analysing sustainable development trends and impacts such as urbanization.

The geoportal is spatially enabled to perform a wide range of spatial analytical functions through the integration of the PostGIS onto the PostgreSQL relational database. Some of the basic functions currently performed by the geoportal include buffer analysis, map overlay, spatial filtering, attribute queries, spatial queries, distance querying, and calculation of areas and length. The attribute and spatial querying functionality are shown in Figures 19 and 20 respectively. Figure 21 illustrates the 
buffering capability of the geoportal in the selection of schools within a specified distance from a selected school.

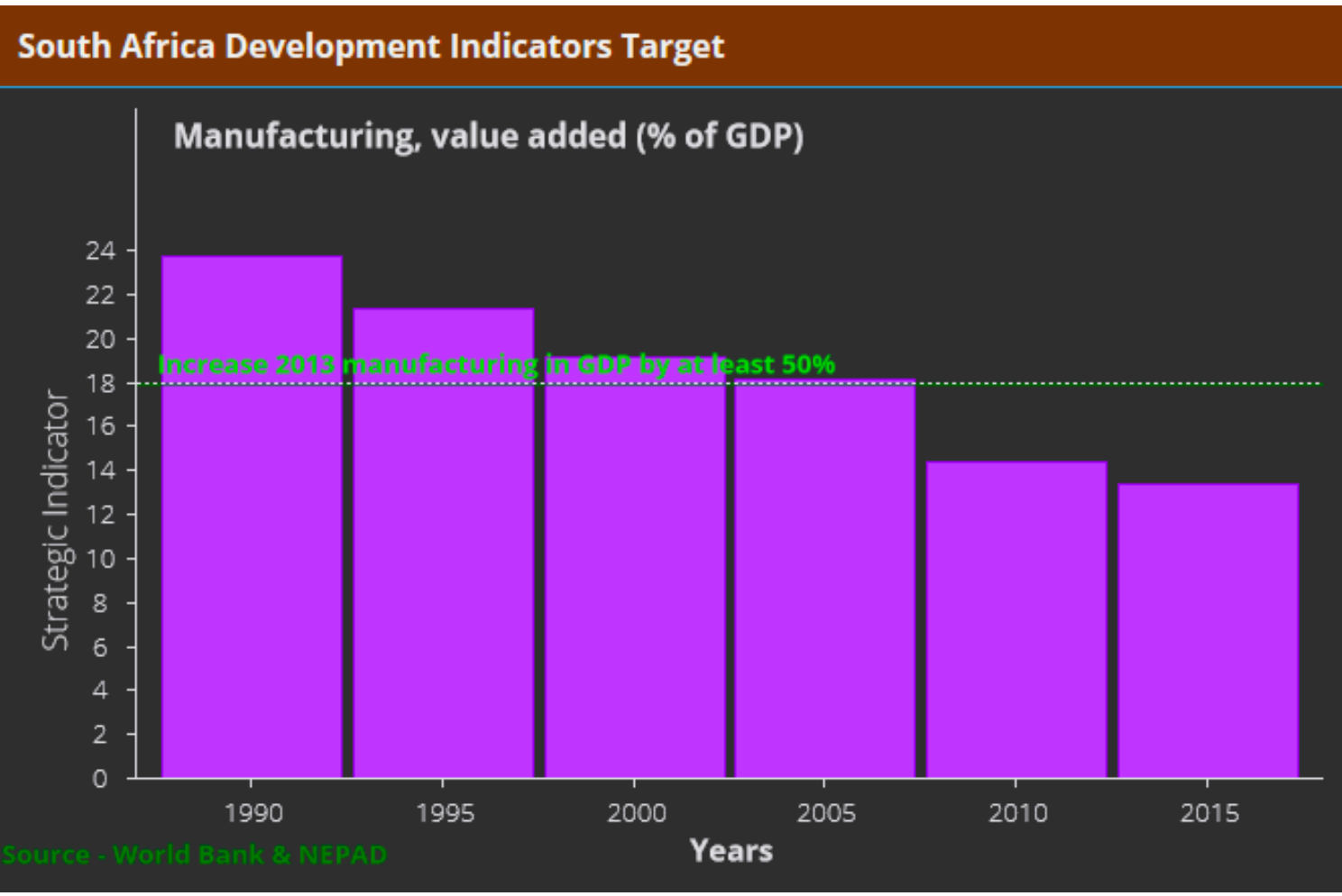

Figure 13. Manufacturing, value-added information displayed by the front end.

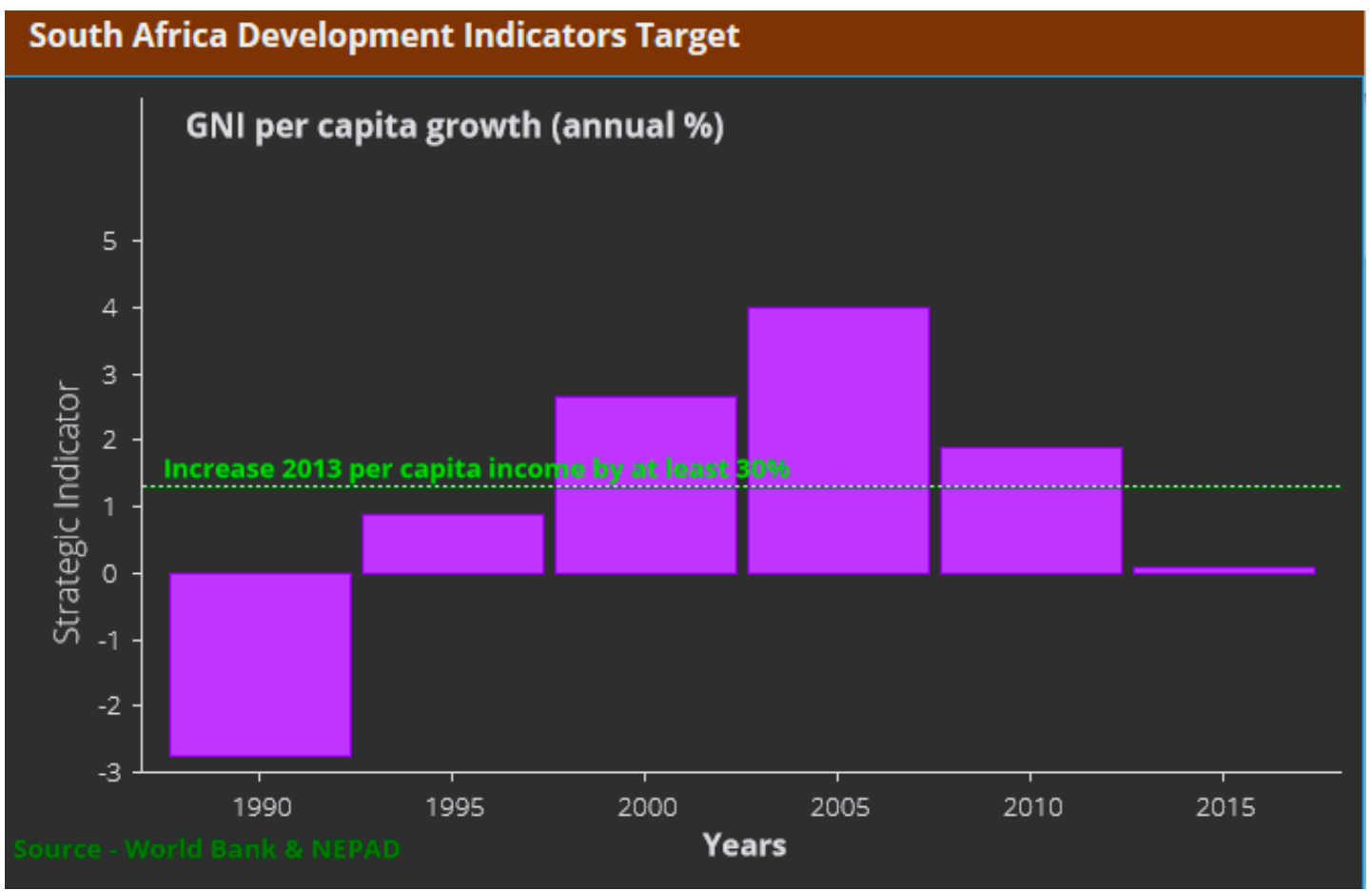

Figure 14. Gross national income (GNI) per capita growth information displayed by the front end. 


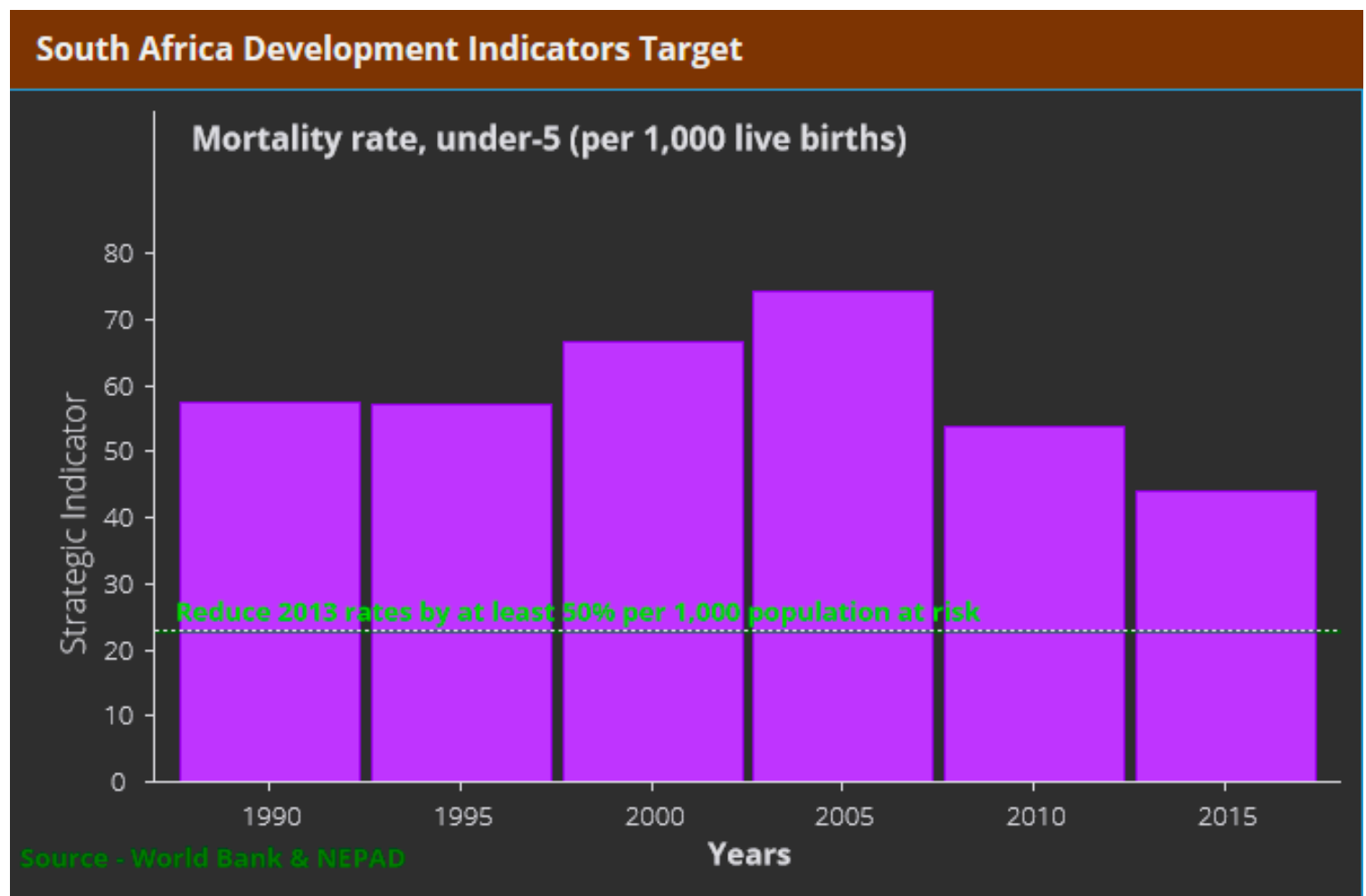

Figure 15. Mortality rate information displayed by the front end.

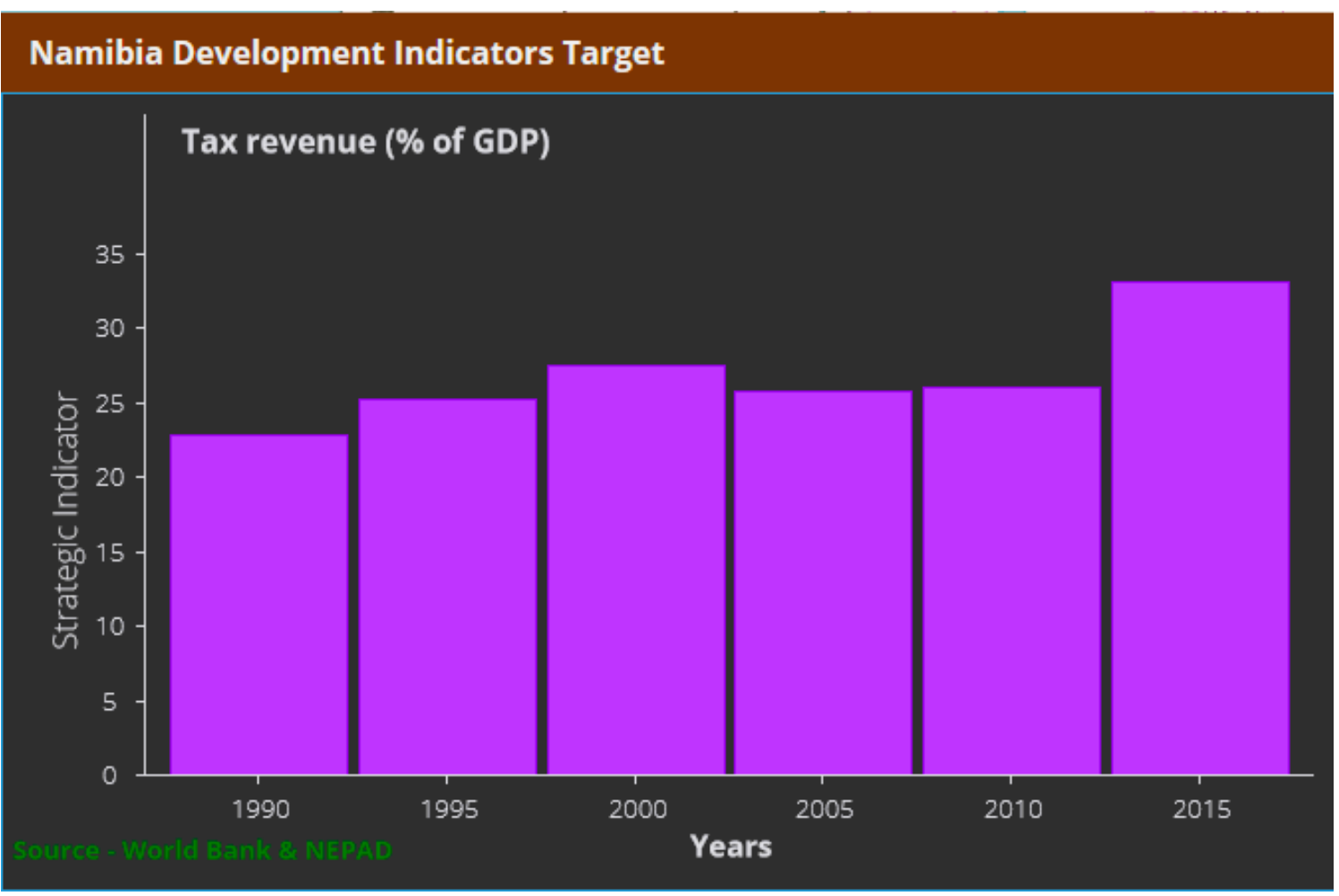

Figure 16. Tax revenue information displayed by the front end. 


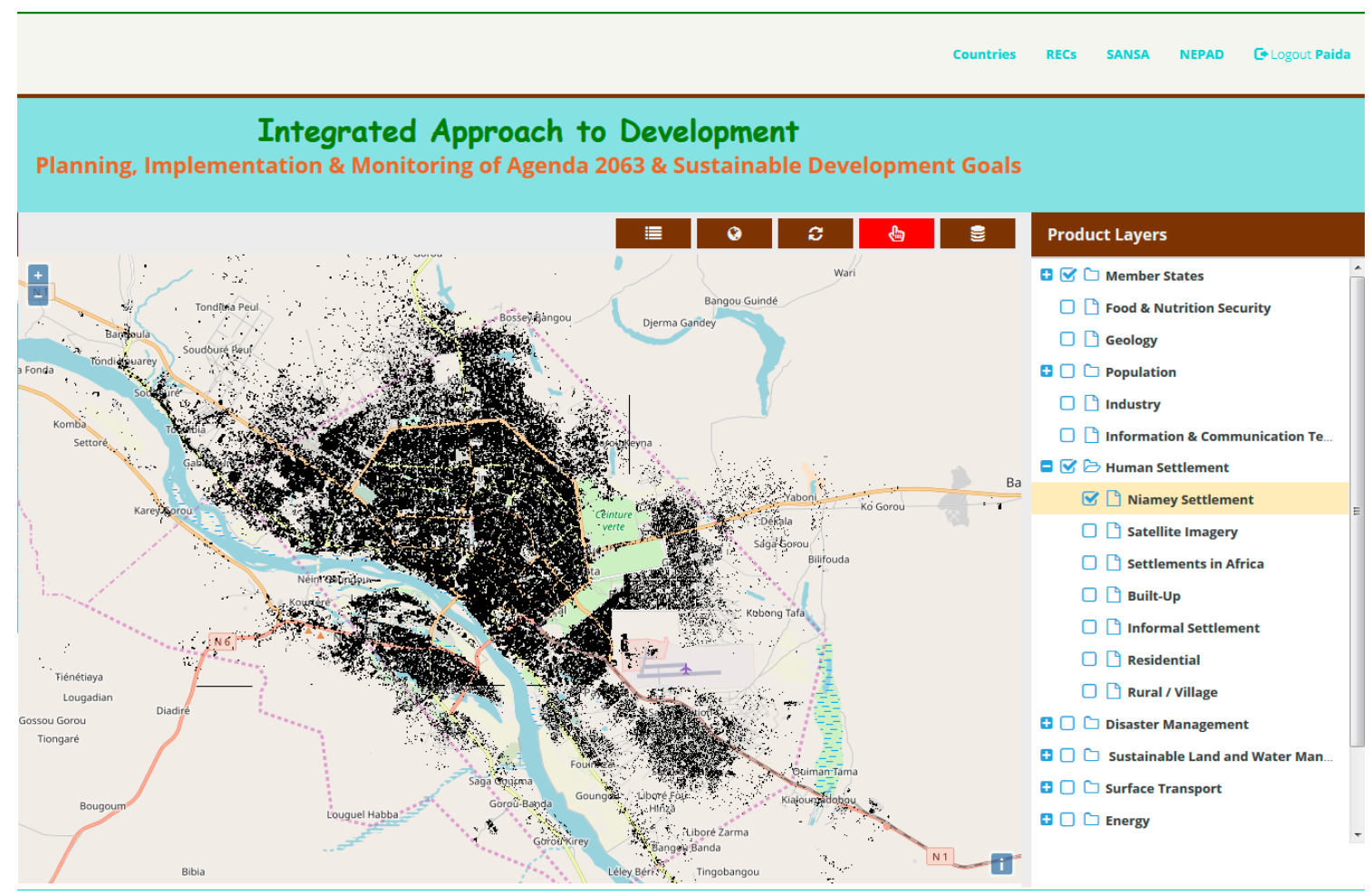

Figure 17. Map overlay operations. Human settlements layer over the city of Niger.

Countries RECS SANSA NEPAD CoLogout Paida

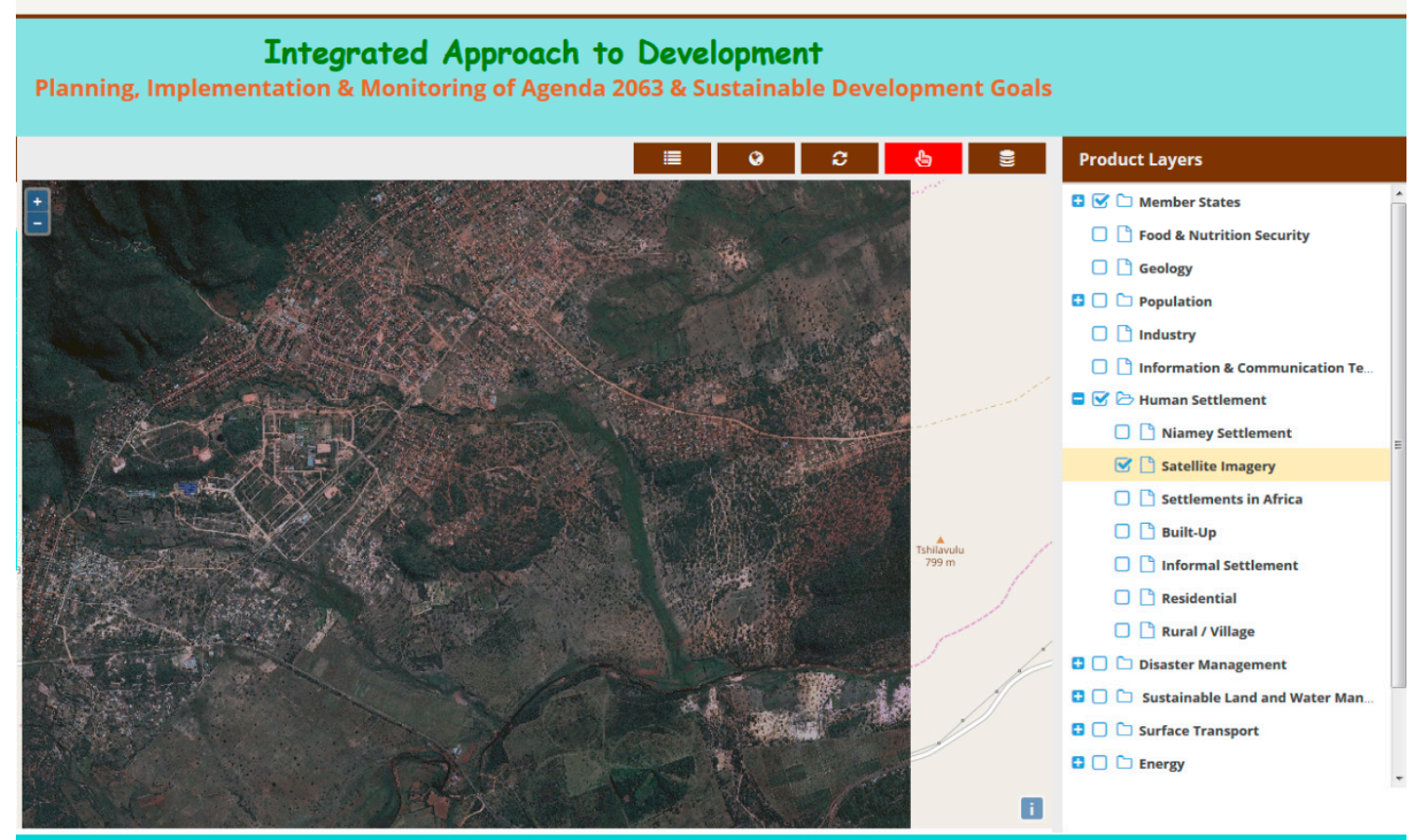

Figure 18. Satellite image data overlays. 


\section{Ask Questions}

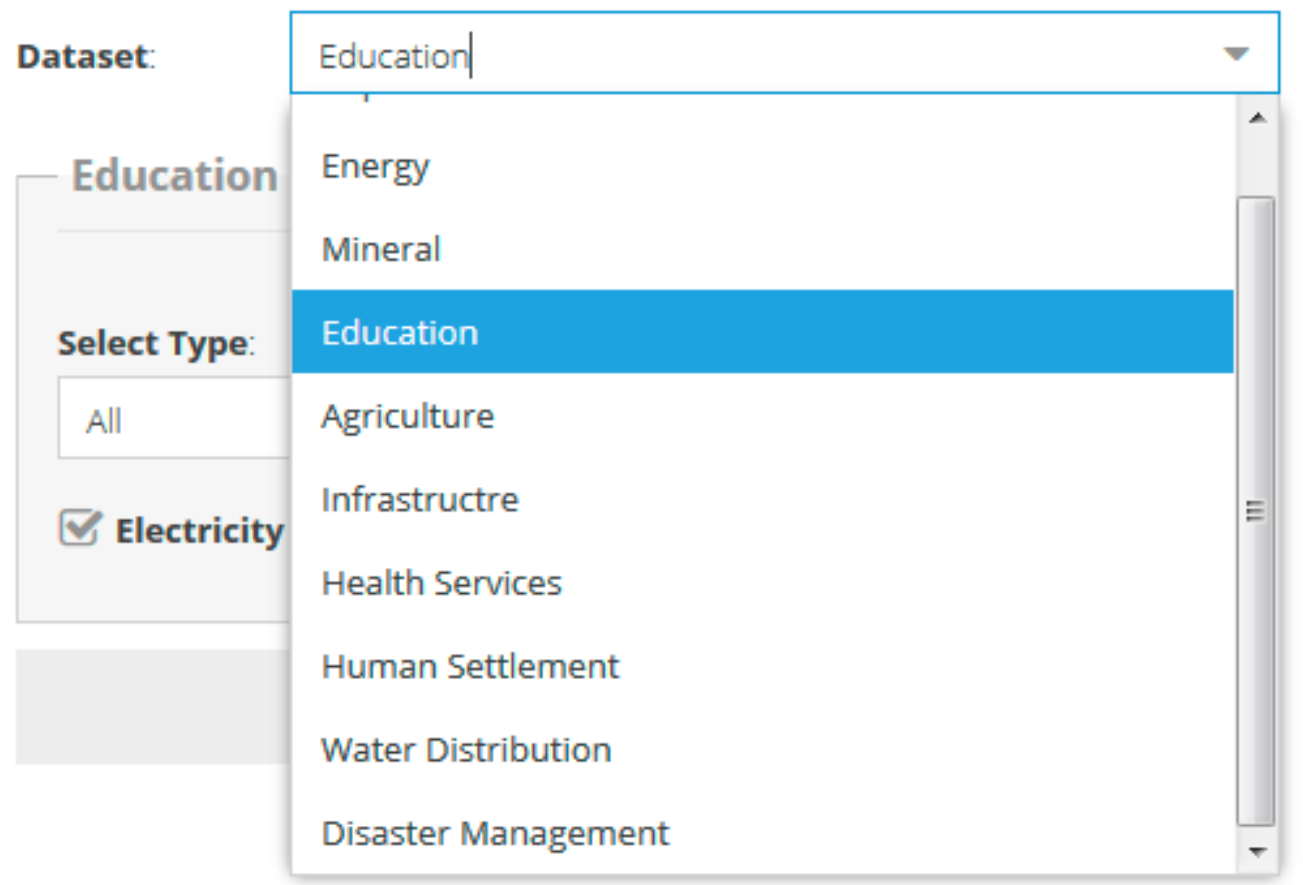

Figure 19. Attribute querying capability.

\begin{tabular}{|c|c|c|c|c|c|c|c|c|c|c|c|c|}
\hline \multicolumn{13}{|c|}{ Education } \\
\hline & & \multirow{2}{*}{ Name } & \multirow{2}{*}{ Type } & \multirow{2}{*}{ Drop Out } & \multicolumn{2}{|c|}{ Pupil } & \multirow{2}{*}{ Subjects } & \multirow{2}{*}{ Electricity } & \multirow{2}{*}{ Water } & \multirow{2}{*}{ Computers } & \multirow{2}{*}{ Province } & \\
\hline & & & & & Boys & Girls & & & & & & \\
\hline$\square$ & 1 & MBANGWA PRIMARY & PUBLIC & 47 & 737 & 64 & 7 & Yes & Yes & 35 & LP & \\
\hline$\square$ & 2 & 2 NOKANE PRIMARY & PUBLIC & 47 & 737 & 64 & 7 & Yes & Yes & 35 & LP & \\
\hline$\square$ & 3 & 3 VUYANI PRIMARY & PUBLIC & 47 & 737 & 64 & 7 & Yes & Yes & 35 & LP & \\
\hline$\square$ & 4 & 4 MASALA PRIMARY & PUBLIC & 47 & 737 & 64 & 7 & Yes & Yes & 35 & LP & \\
\hline$\nabla$ & 5 & CHARLIE RHANGANI PRIMARY & PUBLIC & 47 & 737 & 64 & 7 & Yes & Yes & 35 & LP & \\
\hline$\square$ & 6 & LAWLEY PRIMARY SCHOOL ... & PUBLIC & 47 & 737 & 64 & 7 & Yes & Yes & 35 & GT & \\
\hline$\square$ & 7 & TJOKKERLAND ACADEMY & INDEPENDE... & 47 & 737 & 64 & 7 & Yes & Yes & 35 & GT & \\
\hline$\square$ & 8 & 3 ROSSLYN PRIMARY SCHOOL & PUBLIC & 47 & 737 & 64 & 7 & Yes & Yes & 35 & GT & \\
\hline$\square$ & 9 & AFRICAN SCHOOL FOR EXCE... & INDEPENDE... & 47 & 737 & 64 & 7 & Yes & Yes & 35 & GT & \\
\hline$\square$ & 10 & EMYEZWENI NONFANELEKO... & INDEPENDE... & 47 & 737 & 64 & 7 & Yes & Yes & 35 & we & \\
\hline$\square$ & 11 & ACW KINDERSENTRUM (GER... & INDEPENDE... & 47 & 737 & 64 & 7 & Yes & Yes & 35 & wc & \\
\hline$\square$ & 12 & ALBERT COLLEGE & INDEPENDE... & 47 & 737 & 64 & 7 & Yes & Yes & 35 & we & \\
\hline$\square$ & 13 & LITTLE ACHIEVERS & PUBLIC & 47 & 737 & 64 & 7 & Yes & Yes & 35 & LP & \\
\hline$\square$ & 14 & ZIZAMELE EDUCARE CENTRE & INDEPENDE... & 47 & 737 & 64 & 7 & Yes & Yes & 35 & we & \\
\hline$\square$ & 15 & NAGENG PRIMARY SCHOOL & PUBLIC & 47 & 737 & 64 & 7 & Yes & Yes & 35 & GT & - \\
\hline
\end{tabular}

Figure 20. Spatial querying capability. 


\section{CHARLIE RHANGANI PRIMARY Spatial Query $\quad x$}

\begin{tabular}{|l|l|}
\hline Select Facility: & Radius $(\mathrm{Km}):$ \\
\hline All school within & \\
\hline All school within & \\
\hline All health facilities within \\
All police stations within \\
Closest main road
\end{tabular}

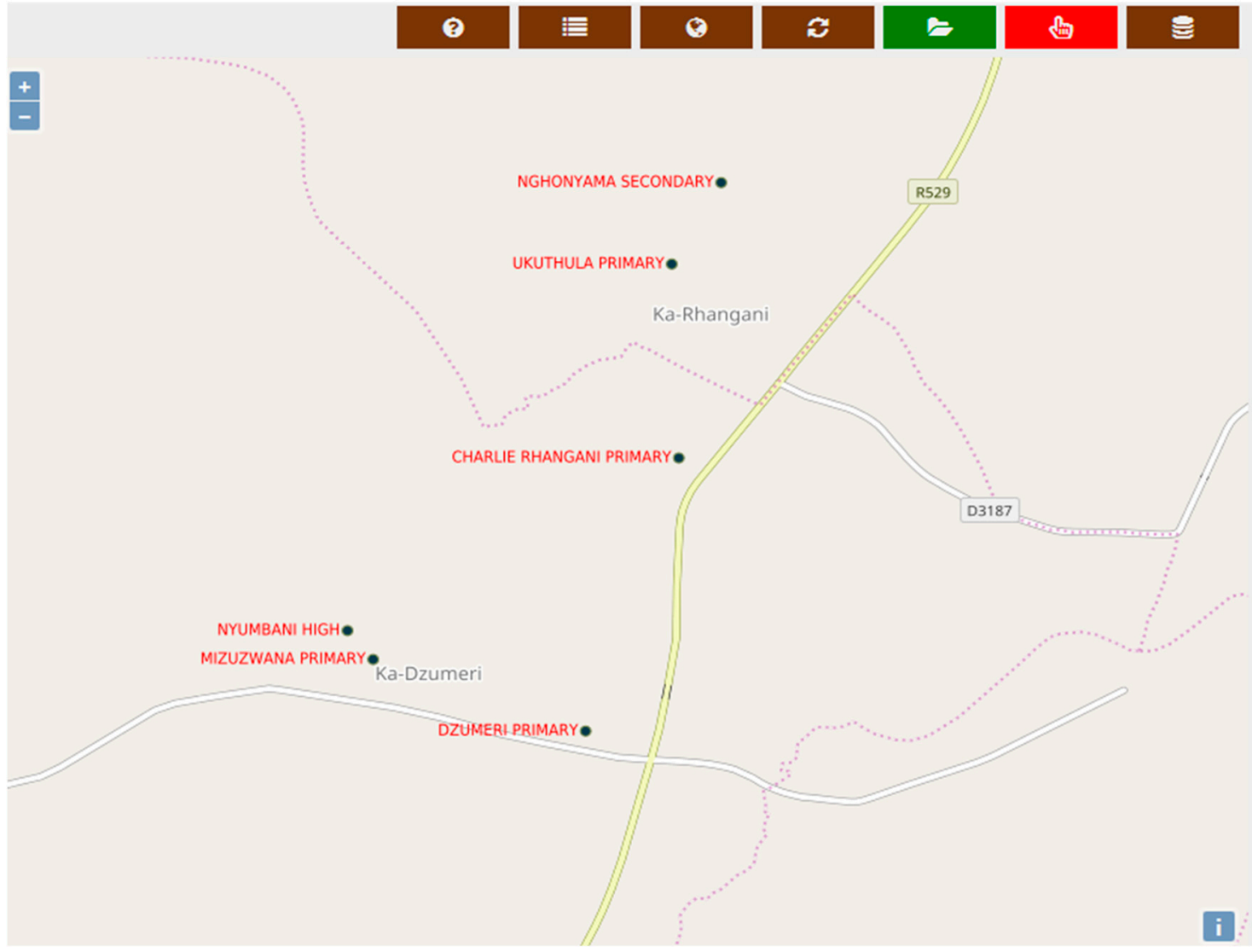

Figure 21. Buffering schools within a $5 \mathrm{~km}$ radius of Charlie Rhangani Primary.

\section{Feedback from User Seminars}

In all the user workshops conducted, the participants supported the need for the piloted Geoportal as it provides an integrated digital platform for the discovery, visualization, analysis, upload, and download of development statistics for Africa. The geoportal was seen as a fit-for-purpose tool that will support the monitoring and evaluation of Agenda 2063 targets. While participants supported the geoportal functionality and the basis for its development, some recommendations were provided. Pertinent issues that emerged from the workshop included issues regarding data policy and custodianship, mandates for Agenda 2063 and SDG reporting in various countries, access rights, maintenance of data integrity, validation of data sources, data provenance and metadata, 
geoportal security, the synergy between Agenda 2063 targets and the UN SDGs, data collection methods, and data standards. The participants also emphasized the need to provide training to public officials involved in planning, monitoring, and evaluation on how to use the geoportal to access and discover information for analysis and reporting. Participants also recognized the need for a federated system when upscaling the prototype geoportal into a functional geoportal. A key message that also emerged from the workshop was the need for linking the geoportal to other existing geoportals and development-oriented systems to facilitate data harvesting, interoperability, and synergy with countries and regional economic communities. These recommendations were accepted and will be implemented when upgrading the prototype geoportal.

\section{Discussion and Future Direction}

While our prototype geoportal provided the basic functionalities of a geoportal such as data uploading, querying, visualization, graphical functionality, and downloading capability for demonstration purposes, additional functionality is required for an operational geoportal. Future work will be oriented towards enhancing the analytical capability of the geoportal, dynamic visualization, 3-dimensional visualization, metadata cataloguing, provenance tracking, user feedback functionality, and enhancement of the search functionality using grid-enabled search techniques and web crawlers. Katumba [34] provides a valuable overview of advanced search techniques optimized to improve the discovery of geospatial data on the internet. Given the sheer volume and variety of data to be stored on the geoportal, cloudification of the geoportal will be considered. Iosifescu-Enescu [35] indicates that auto-scalable cloud-based architectures using virtual servers and autoscaling have advantages such as rapid elasticity and on-demand self-service. Alternatively, a federation or hybrid system architecture that is capable of connecting to multiple distributed systems will also be considered. Recently, Jiang [31] suggested solutions and recommendations regarding geoportal architectures, services, and state of the technologies to deal with common geoportal problems. Li [36] showcased many visualization techniques based on spatial scale and temporal primitives that have the potential for adoption. The visual information seeking mantra (VISM) technique showcased in their paper is beneficial when exploring data at a global, group, and local scale while classic visualization templates offer an opportunity to present charts and graphs to support monitoring and evaluation.

While we managed to demonstrate the spatial functionality of the geoportal, future work will be dedicated towards enhancing this functionality. Future upgrades will be directed towards the integration of the open-source R statistical software to enhance the statistical and spatial data analytical capability of the geoportal. Advanced spatial analysis is currently feasible through a QGIS software WMS connection. Future developments of the geoportal will also be directed on customizing the geoportal in line with the requirements of the various user segments. The front end interface of the geoportal accessed will be configured by changing language options and providing menu choices and buttons that are specific to countries and regional economic communities. Using interactive graphical customisation, the geoportal will also be adapted to change colour schemes and icons in line with the user needs. Planning officers that use the geoportal frequently for reporting purposes will have access to programmed functionality aimed for optimized reporting. Customization of the geoportal will also include the provision of spatial and statistical analysis tools and data translators designed to support advanced spatial planning and analysis. Besides, database management systems will be customized to enable connectivity and interoperability with other ratified geographically distributed spatial databases.

The operational implementation of the geoportal should conform to international geospatial standards such as the OGC, Spatial Data Infrastructure (SDI), Dublin Core metadata standard, Schema.org standard, and 1SO/TC211 standards. Best practices and guidelines provided by UN Statistics such as the Fundamental Principles of Official Statistics, Shared Guiding Principles for Geospatial Information Management and the Integrated Geospatial Information Framework will also 
be adopted to ensure data quality. Data integrity shall also be ensured by a peer-review process as set out by in the African Union Implementation Plan.

From the functionality illustrated in this paper and feedback collected from the user seminars, it is evident that the Agenda 2063 Geoportal will play a significant role in providing geoinformation products and services necessary to support evidence-based integrated spatial planning. It is foreseen that with the demonstrated capability, the Agenda 2063 Geoportal has the potential to play an important role assisting the tracking of the sustainable development indicators over time, and will support data-driven decision making across sectors, within continental, regional, national, and sub-national spheres. The geoportal implemented in this project provides a credible mechanism to share credible, timely, and consistent data and information to support sustainable development enabling efficient monitoring and evaluation. Timely information enables timely decision-making.

Future development options would look at the potential of a geographically distributed geoportal. While noting the data storage complexity associated distributed GIS databases over centralized databases, Kumar [37] highlights a number of distributed GIS databases are more efficient in terms speed, reliability, and storage efficiency when sharing large heterogeneous datasets. Distributed geoportals are particularly suitable when users require real-time responses of their queries and when the geoportal has interactive graphics. The deployment of the geoportal onto a cloud platform is another alternative that could be considered in order to achieve high operational efficiency in terms of data storage, upload, and analytical capabilities. Cloud computing is increasingly being used in the geospatial sciences to storage and analyse large datasets such as satellite imagery. Amazon web services (AWS) have already demonstrated the feasibility of hosting such as geoportal on a cloud platform through the hosting of the Africa Regional Data Cube and Open Data Cube Initiatives (https://aws.amazon.com/blogs/publicsector/tag/africa-regional-data-cube/, 2019). The integration of the geoportal with emerging digital platforms for accessing and analysing satellite imagery for assessing environmental conditions over the continent will enhance the capability of the geoportal. Interfacing the geoportal with the Digital Earth Africa data cube platform (http://www.ga.gov.au/digitalearthafrica), for instance, will open up opportunities for long-term time series analysis and change detection of urban areas, surface water resources, croplands, vegetation cover, land degradation, and other natural resources necessary to achieve Africa's development agenda.

\section{Conclusions}

Our prototypic geoportal implementation demonstrates that a web- geoportal can be used for accessing, integrating, visualizing, analysing, and disseminating multi-datasets to support the monitoring of the Agenda 2063 sustainable development indicators. It provides a single data platform for integrating multiple data sources that can be compared over space and time. Most importantly, the geoportal allows governments across Africa to share their development information in support of Agenda 2063 and enables them to visualize and to compare their data with those of other African countries on a common online platform. Timely information is a critical input in the design, monitoring, and evaluation of multi-sectoral sustainable development policies. The integration of satellite imagery into the Geoportal provides a data visualization functionality that can be used to visually illustrate the current situations with regards to access to basic services such as schools, health care facilities, electricity, urban and infrastructure development, flooding events, agriculture, and surface water resource evaluations. The graphical functionality of the Geoportal allows users to monitor trends between different countries and regional blocks. The Geoportal provides an open and common platform for sharing, monitoring, and evaluation in support of evidence-based planning, reporting, and decision-making. In this paper, we have been able to demonstrate that while most geoportals have a national and project focus, it is feasible to have a continent-wide geoportal that serves a common digital platform for data discovery, visualization, storage, analysis, uploading, and dissemination. This geoportal will assist in providing access to sustainable development data aligned with Agenda 2063 and will enable the user to compare development trends across Africa. It will also allow development 
funders to quickly access information on the impact of their development programmes in different regions of the continent on a data-rich web platform.

The success of a geoportal is evaluated by its functionality for end users, geoportal management, geoportal data security and geoportal interoperability, and interface customization. We aimed to develop a demonstration geoportal through rapid prototyping and concurrent engineering. Through the demonstration held with the regional economic communities in Africa, the African Union Commission, and selected member states the value of a geoportal for integrated reporting, monitoring, and evaluation were ascertained. The Geoportal was seen as a pragmatic and unified way of consolidating development information to support the monitoring of the Agenda 2063 goals. The user functionality demonstrated by the portal in terms of data visualization, querying, discovery, analysis, charting, and sharing is valuable for integrated planning, monitoring, and evaluation. Access rights are a key issue in information management, in this, we successfully showed the functionality of the monitoring and evaluation geoportal for by providing registration and access rights to three levels of users that are can be authenticated and validated. The uploading of official and credible information was also an important consideration in the development of this geoportal. We achieved this through a validation done after registration on the system, whereby rights to upload relevant information is only granted to approved officials in member states. The Geoportal management is ensured by granting administrator and publisher User-IDs and passwords. Geoportal data security was achieved through user authentication options available in PostgreSQL. To ensure interoperability, the geoportal supports a wide range of metadata standards and a variety of common electronic data communication standards. Given the successful demonstration of this live geoportal prototype, a consolidated user requirement will be drawn up and an operational geoportal will be developed as the next step. More advanced geospatial and statistical analytical functionality will also be added to the geoportal as it evolves into its operational phase, in compliance with the user requirements. Future considerations will also focus on data policies and data security matters. The full implementation of the Agenda 2063 geoportal into operational mode will be critical to support the tracking performance indicators and evidence-based policy and decision making in Africa.

Author Contributions: Paidamwoyo Mhangara conceptualized, wrote, edited, and submitted the paper and led the implementation of the Geoportal. Asanda Lamba wrote the paper and implemented the Geoportal. Willard Mapurisa wrote, edited the paper and assisted in implementing the Geoportal. Naledzani Mudau wrote and edited the paper.

Funding: This research received no external funding.

Acknowledgments: We are highly indebted to Mohamed Abdisalam, Martin Bwalya, and Simon Kisira all from NEPAD-AUDA for their valuable contribution in guiding the development of this geoportal.

Conflicts of Interest: The authors declare no conflict of interest.

\section{References}

1. DeGhetto, K.; Gray, J.R.; Kiggundu, M.N. The African Union's Agenda 2063: Aspirations, challenges, and opportunities for management research. Afr. J. Manag. 2016, 2, 93-116. [CrossRef]

2. Sirisena, P.; Noordeen, F.; Kurukulasuriya, H.; Romesh, T.A.; Fernando, L. Effect of Climatic Factors and Population Density on the Distribution of Dengue in Sri Lanka: A GIS Based Evaluation for Prediction of Outbreaks. PLoS ONE 2017, 12, e0166806. [CrossRef]

3. Vickers, B. A Handbook on Regional Integration in Africa: Towards Agenda 2063; Commonwealth Secretariat; Marlborough House: London, UK, 2017.

4. African Union. AGENDA 2063: The Africa We Want Framework Document Adopted in September; African Union Commission: Addis Ababa, Ethiopia, 2015.

5. African Union. Agenda 2063: First Ten-Year Implementation Plan 2014-2023; African Union Commission: Addis Ababa, Ethiopia, 2015. 
6. African Union. Others MDGs to Agenda 2063/SDGs Transition Report 2016: 2016 Towards an Integrated and Coherent Approach to Sustainable Development in Africa; African Union Commission: Addis Ababa, Ethiopia, 2016.

7. NEPAD. Integrated Territorial Development. Application of Geographic Information System for A63; Springer: Basel, Switzerland, 2015.

8. United Nations. World Population Prospects 2019. 2019. Available online: https://population.un.org/wpp/ (accessed on 4 September 2019).

9. Man, W.E.; van den Toorn, W.H. Culture and the adoption and use of GIS within organisations. Int. J. Appl. Earth Obs. Geoinf. 2002, 4, 51-63.

10. Scott, G.; Rajabifard, A. Sustainable development and geospatial information: A strategic framework for integrating a global policy agenda into national geospatial capabilities. Geo-Spatial Inf. Sci. 2017, 20, 59-76. [CrossRef]

11. Bao, Y.-W.; Yu, M.-X.; Wu, W. Design and Implementation of Database for a webGIS-based Rice Diseases and Pests System. Procedia Environ. Sci. 2011, 10, 535-540. [CrossRef]

12. Harris, T.M.; Elmes, G.A. The application of GIS in urban and regional planning: A review of the North American experience. Appl. Geogr. 1993, 13, 9-27. [CrossRef]

13. Jovanovic, V.; Njegus, A. The application of GIS and its components in tourism. Yugosl. J. Oper. Res. 2008, 18, 261-272. [CrossRef]

14. Sheppard, E. GIS and Society: Towards a Research Agenda. Cartogr. Geogr. Inf. Syst. 1995, 22, 5-16. [CrossRef]

15. Frolova, N.; Bonnin, J.; Larionov, V.; Ugarov, A. Complexity in seismic risk assessment at different levels with GIS technology application. In Engineering Geology for Society and Territory; Springer: Cham, Germany, 2015; pp. 381-385.

16. Gharbia, S.S.; Gill, L.; Johnston, P.; Pilla, F. Multi-GCM ensembles performance for climate projection on a GIS platform. Model. Earth Syst. Environ. 2016, 2, 102. [CrossRef]

17. Van Halderen, G.; Minchin, S.; Brady, M.; Scott, G. Integrating statistical and geospatial information, cultures and professions: International developments and Australian experience. Stat. J. IAOS 2016, 32, 1-14. [CrossRef]

18. Arozarena, A.; Villa, G.; Valcárcel, N.; Pérez, B. INTEGRATION OF REMOTELY SENSED DATA INTO GEOSPATIAL REFERENCE INFORMATION DATABASES. UN-GGIM NATIONAL APPROACH. Int. Arch. Photogramm. Remote Sens Spat. Inf. Sci. 2016, 41.

19. Anderson, K.; Ryan, B.; Sonntag, W.; Kavvada, A.; Friedl, L. Earth observation in service of the 2030 Agenda for Sustainable Development. Geo-Spat. Inf. Sci. 2017, 20,77-96. [CrossRef]

20. GEO. SDG Coordination across GEO Work Programme Activities; Group on Earth Observation: Geneva, Switzerland, 2017.

21. Masó, J.; Serral, I.; Domingo-Marimon, C.; Zabala, A. Earth observations for sustainable development goals monitoring based on essential variables and driver-pressure-state-impact-response indicators. Int. J. Digit. Earth 2019, 1-19. [CrossRef]

22. Menon, S.; Karl, J.; Wignaraja, K. Handbook on planning, monitoring and evaluating for development results. UNDP Eval. Off. N. Y. 2009.

23. Maguire, D.J.; Longley, P.A. The emergence of geoportals and their role in spatial data infrastructures. Comput. Environ. Urban Syst. 2005, 29, 3-14. [CrossRef]

24. Vockner, B.; Mittlböck, M. Geo-Enrichment and Semantic Enhancement of Metadata Sets to Augment Discovery in Geoportals. ISPRS Int. J. Geo-Inf. 2014, 3, 345-367. [CrossRef]

25. Crăciunescu, V.; St, C.; Ovejeanu, I. Developing an open Romanian geoportal using free and open source software. Geogr. Tech. 2008, 3, 15-20.

26. Foerster, T.; Schäffer, B. A client for distributed geo-processing on the web. In Proceedings of the International Symposium on Web and Wireless Geographical Information Systems, Cardiff, UK, 28-29 November; Springer: Berlin/Heidelberg, Germany, 2007; pp. 252-263.

27. Fritz, S.; McCallum, I.; Schill, C.; Perger, C.; See, L.; Schepaschenko, D.; Van Der Velde, M.; Kraxner, F.; Obersteiner, M. Geo-Wiki: An online platform for improving global land cover. Environ. Model. Softw. 2012, 31, 110-123. [CrossRef] 
28. Giff, G.; Van Loenen, B.; Crompvoets, J.; Zevenbergen, J. Geoportals in selected European states: A nontechnical comparative analysis. In Proceedings of the Conference, Small Island Perspectives on Global Challenges: The Role of Spatial Data in Supporting a Sustainable Future, St. Augustine, Trinidad, 25-19 February 2008; pp. 25-29.

29. Lim, E.-P.; Goh, D.H.-L.; Liu, Z.; Ng, W.-K.; Khoo, C.S.-G.; Higgins, S.E. G-Portal: A map-based digital library for distributed geospatial and georeferenced resources. In Proceedings of the 2nd ACM/IEEE-CS Joint Conference on Digital Libraries, Portland, OR, USA, 14-18 July 2002; ACM: New York, NY, USA, 2002; pp. 351-358.

30. Crompvoets, J.; Bregt, A.; de Bree, F.; van Oort, P.; van Loenen, B.; Rajabifard, A.; Williamson, I. Worldwide (Status, Development and) Impact Assessment of Geoportals. FIG Working Week 2005 and GSDI-8. Available online: https://minerva-access.unimelb.edu.au/handle/11343/33848 (accessed on 4 September 2019).

31. Jiang, H.; Van Genderen, J.; Mazzetti, P.; Koo, H.; Chen, M. Current status and future directions of geoportals. Int. J. Digit. Earth 2019. [CrossRef]

32. Veenendaal, B.; Brovelli, M.A.; Li, S. Review of Web Mapping: Eras, Trends and Directions. ISPRS Int. J. Geo-Inf. 2017, 6, 317. [CrossRef]

33. ESRI. ESRI Geoportal Technology. An ESRI ${ }^{\circledR}$ White Paper; ESRI: Redlands, CA, USA, 2009.

34. Katumba, S.; Coetzee, S. Employing Search Engine Optimization (SEO) Techniques for Improving the Discovery of Geospatial Resources on the Web. ISPRS Int. J. Geo-Inf. 2017, 6, 284. [CrossRef]

35. Iosifescu-Enescu, I.; Matthys, C.; Gkonos, C.; Iosifescu-Enescu, C.M.; Hurni, L. Cloud-Based Architectures for Auto-Scalable Web Geoportals towards the Cloudification of the GeoVITe Swiss Academic Geoportal. ISPRS Int. J. Geo-Inf. 2017, 6, 192. [CrossRef]

36. Li, Y.; Wei, B.; Wang, X. A Web-Based Visual and Analytical Geographical Information System for Oil and Gas Data. ISPRS Int. J. Geo-Inf. 2017, 6, 76. [CrossRef]

37. Kumar, L.; Skidmore, A.K.; Knowles, E. Modelling topographic variation in solar radiation in a GIS environment. Int. J. Geogr. Inf. Sci. 1997, 11, 475-497. [CrossRef]

(C) 2019 by the authors. Licensee MDPI, Basel, Switzerland. This article is an open access article distributed under the terms and conditions of the Creative Commons Attribution (CC BY) license (http://creativecommons.org/licenses/by/4.0/). 